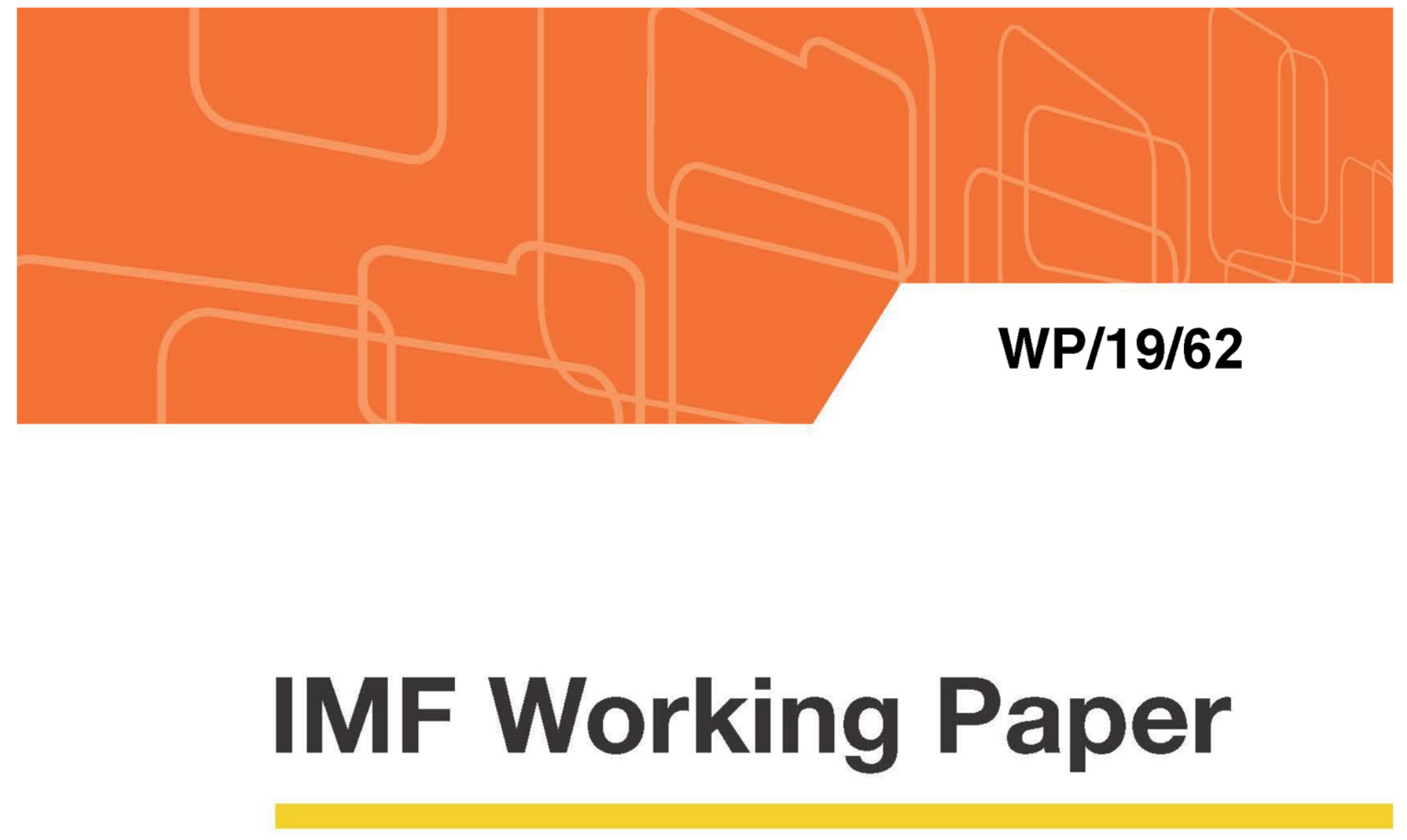

\title{
Some Policy Lessons from Country Applications of the DIG and DIGNAR Models
}

by Daniel Gurara, Giovanni Melina, and Luis-Felipe Zanna 


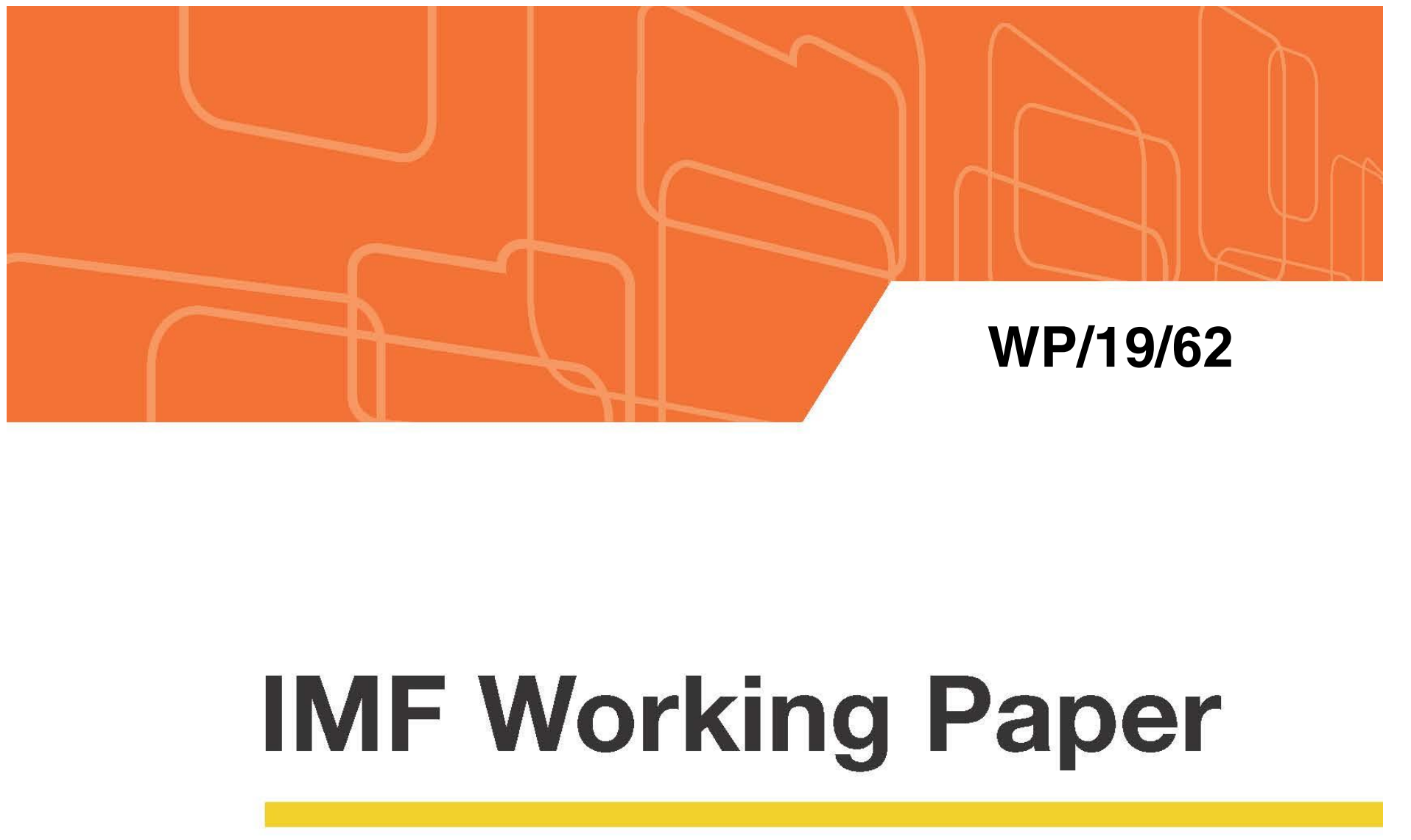

\section{Some Policy Lessons from Country Applications of the DIG and DIGNAR Models}

by Daniel Gurara, Giovanni Melina, and Luis-Felipe Zanna 


\title{
IMF Working Paper
}

Strategy, Policy, and Review Department, Research Department, and

Institute for Capacity Development

\section{Some Policy Lessons from Country Applications of the DIG and DIGNAR Models}

\author{
Prepared by Daniel Gurara, Giovanni Melina, and Luis-Felipe Zanna* \\ Authorized for distribution by Johannes Wiegand, Chris Papageorgiou, and Valerie Cerra
}

March 2019

\begin{abstract}
IMF Working Papers describe research in progress by the author(s) and are published to elicit comments and to encourage debate. The views expressed in IMF Working Papers are those of the author(s) and do not necessarily represent the views of the IMF, its Executive Board, IMF

management, or DFID.
\end{abstract}

\begin{abstract}
Over the past seven years, the DIG and DIGNAR models have complemented the IMF and World Bank debt sustainability framework (DSF) analysis, over 65 country applications. They have provided useful insights in the context of program and surveillance work, based on qualitative and quantitative analysis of the macroeconomic effects of public investment scaling-ups. This paper takes stock of the model applications and extensions, and extract five common policy lessons from the universe of country cases. First, improving public investment efficiency and/or raising the rate of return of public projects raises growth and lowers the risks associated with debt sustainability. Second, prudent and gradual investment scaling-ups are preferable to aggressive front-loaded ones, in terms of private sector crowding-out effects, absorptive capacity constraints, and debt sustainability risks. Third, domestic revenue mobilization helps create fiscal space for investment scaling-ups, by effectively containing public debt surges and their lateron repayments. Fourth, aid smoothens fiscal adjustments associated with public investment increases and may lower the risks of unsustainable debt. Fifth, external savings mitigate Dutch disease macroeconomic effects and serve as fiscal buffers. The paper also discusses how these models were used to estimate the quantitative macro economic effects associated with these lessons.
\end{abstract}

JEL Classification Numbers: Q32; E22; E62; F34.

Keywords: Natural resources; Public Investment; Debt Sustainability; Small Open DSGE Models; Developing Countries.

Author’s E-Mail Address: DGurara@imf.org, GMelina@imf.org, FZanna@,imf.org

\footnotetext{
* The DIG and DIGNAR models and the related country applications of these frameworks have been the work output of numerous talented staff at the IMF. Our main contribution in this paper has been to collect, organize, and summarize this work, with excellent research assistance by Jun Ge We have worked and led some of the country applications and, in the case of Giovanni and Felipe, contributed to the development of the original frameworks. But, to a great extent, the credit of this policy research project should go to the following people: Andy Berg, who had the idea of designing a model-based framework to complement the IMF-WB DSF tool, contributed extensively to the design of these models, and insisted on following this line of work more generally for development issues to improve policy analysis in LICs at the Fund; Cathy Pattillo who also contributed to the design of these frameworks and encouraged and supported their policy use at the Fund; Ed Buffie, who was the mastermind of the DIG model and some of the key extensions; Rafael Portillo and Susan Yang who also helped build these models and led some of the country applications; Michele Andreolli, Manoj Atolia, Enrico Berkes, Alessandro Cantelmo, Will Clark, Jun Ge, Matteo Ghilardi, Nathalie Gonzalez, Pranav Gupta, Salifou Issoufou, Malangu Kabedi-Mbuyi, Grace Li, Ricardo Marto, Ioana Moldovan, Constant Lonkeng Ngouana, and Dawit Tessema for their work in the country applications. We are grateful to Aiko Mineshima, Vina Nguyen and Carlo Pizzinelli for useful comments. This paper is part of a research project on macroeconomic policy in low-income countries supported by U.K.'s Department for International Development (DFID). All remaining errors are ours.
} 


\section{Table of Contents}

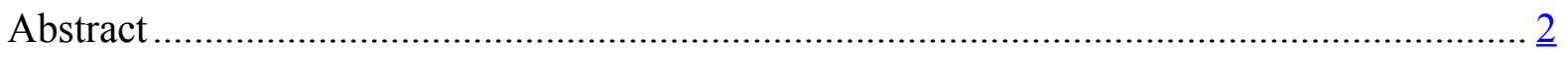

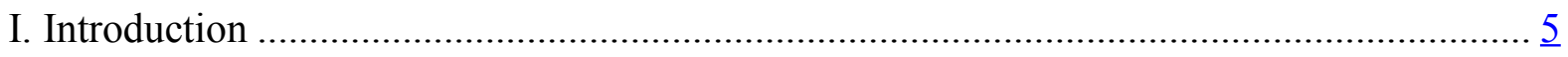

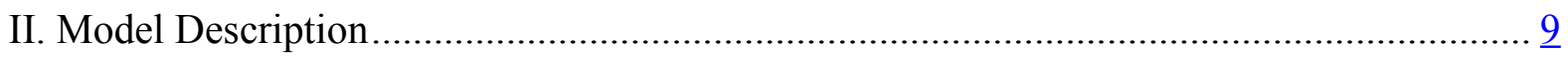

A. The Investment-Growth Nexus.................................................................... 10

B. The Fiscal Adjustment. ..................................................................................... 11

C. The Private Sector Response........................................................................ 13

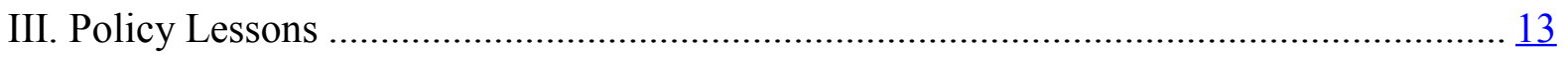

A. Improving Public Investment Efficiency and/or Raising the Rate of Return of Public

Projects Boosts Growth and Lowers the Risks of Debt Sustainability........................... 14

B. Prudent and Gradual Public Investment Scaling-Ups are Preferable to Aggressive Front-

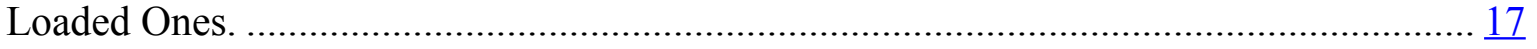

C. Domestic Revenue Mobilization Helps Create Fiscal Space for Investment Scaling-Ups, by Containing Public Debt Surges and their Repayments. .......................................... 21

D. Aid Smoothens Fiscal Adjustments Associated with Public Investment Increases and may Lower the Risks of Unsustainable Debt....................................................... 24

E. External Savings Help Mitigate Dutch Disease Effects and Serve as Fiscal Buffers. ... 26

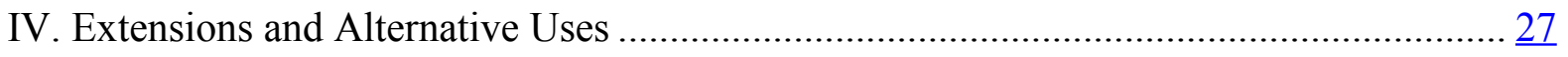

A. Introducing an Energy Sector. ......................................................................... 27

B. Using the DIG Model to Interpret and Analyze DSA Projections.............................. 29

C. Investing in Public Infrastructure: Roads or Schools? ............................................. 30

D. Harnessing Resource Wealth for Inclusive Growth in Fragile States......................... $\underline{32}$

E. “Growth-Friendly”" Fiscal Consolidations............................................................ 33

F. Building Resilience to Natural Disasters.............................................................. 34

G. Balancing Social and Security Spending. ........................................................ 35

H. Governance Reforms...................................................................................... $\underline{36}$

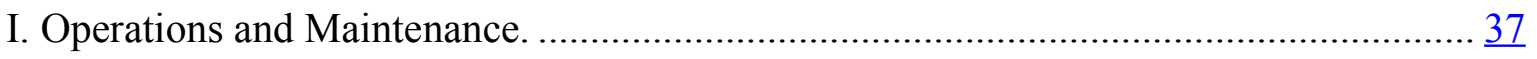

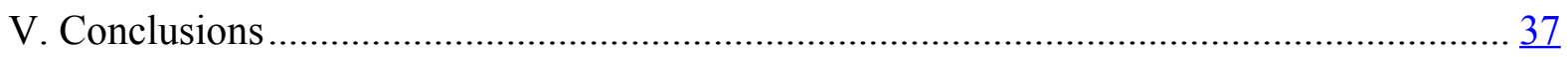

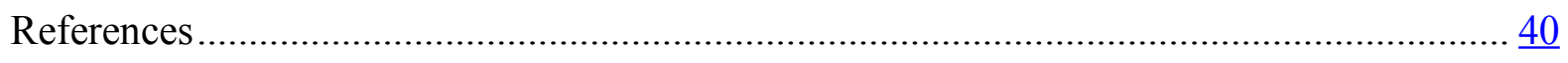

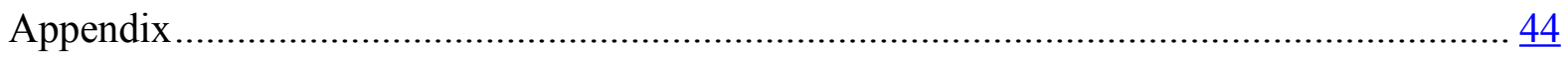

A. List and Web Links of Country Applications ...................................................... 44 


\section{Figures}

Figure 1: Country Applications of the DIG and DIGNAR Models..................................... 7

Figure 2: Putting Together the Pieces.......................................................................... $q$

Figure 3: The Role of Improving Public Investment Efficiency. .................................... 15

Figure 4: Better Project Selection Enhances the Return on Public Capital. ........................ 16

Figure 5: Crowding-Out Effects on Private Demand of a Prudent Versus an Aggressive

Public Investment Scaling-Up.............................................................................. 18

Figure 6: The Role of Absorptive Capacity Constraints on the Effects of a Gradual Versus an

Aggressive Public Investment Scaling-Up. .................................................................. 19

Figure 7: Public Debt Effects of Gradual vs Aggressive Public Investment Scaling-Up....... 21

Figure 8: The Macroeconomic Effects of Tax Reforms............................................. 23

Figure 9: Public Investment Scaling-Ups Under Different Financing Schemes. ................. 24

Figure 10: The Role of Concessional Financing in Smoothing Fiscal Consolidation and

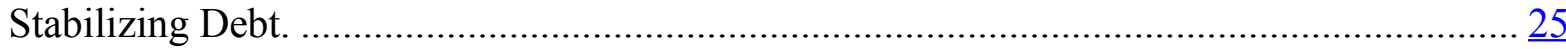

Figure 11: The Role of External Savings.................................................................. 26

Figure 12: External Commercial Borrowing and Bank Borrowing in the DIG Model with an

Energy Sector................................................................................................ 28

Figure 13: Inverting the Model Dynamics: Counterfactual Simulations for Per Capita GDP

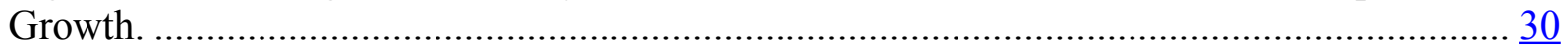

Figure 14: Welfare and Share of Schools in the Public Investment Scaling-Up................. $\underline{31}$

Figure 15: The Macroeconomic Impact of Social Transfers. ............................................ $\underline{32}$

Figure 16: The Effects of Expenditure-Based versus Revenue and Expenditure-Based Fiscal

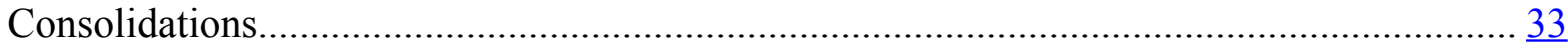

Figure 17: Tax and Debt Financed Reconstruction, After a Natural Disaster..................... $\underline{34}$

Figure 18: The Compounded Security Effect of a Permanent Cut in Foreign Aid................ $\underline{35}$

Figure 19: The Effects of Governance Reforms....................................................... $\underline{36}$ 


\section{INTRODUCTION}

The extent and quality of infrastructure constrain growth in developing countries. Scaling up public investment in infrastructure is thus a key pillar in the national development strategies of several developing countries and a component of the 2030 Development Agenda. Policy choices on public infrastructure provision involve several distinct crucial decisions on the mix of projects to undertake and the pace at which public investment should be increased. They also involve important considerations regarding the effects on growth, absorption capacity constraints, the efficiency and return on investment, and the implications for public debt sustainability, among others (IMF, 2015). With rising debt vulnerabilities in many developing countries, these decisions and considerations have become even more critical, since developing countries should aim at scaling-up public investment in infrastructure while maintaining macroeconomic and debt sustainability (IMF, 2018a).

The IMF and World Bank (IMF-WB) debt sustainability framework (DSF) for low-income countries (LICs) continues to help identify overborrowing situations that may endanger macroeconomic stability, including those associated with public investment scaling-ups. However, as discussed in Buffie et al. (2012), this framework has been subject to several criticisms. Eaton (2002), Hjertholm (2003), and Sachs (2002) have argued, for instance, that the DSF is not an internally consistent macroeconomic framework, to the extent that it does not make explicit the linkages between key macroeconomic variables - e.g., the linkages between public investment, borrowing, and growth. Similarly, Wyplosz (2007) criticizes the DSF for assuming that governments do not react to shocks, contradicting empirical evidence that primary balances respond to rising public debt, and making debt sustainability assessments unnecessarily conservative.

To analyze the effects of public investment plans on growth and debt sustainability in developing countries, while addressing some of the criticisms to the DSF, Fund staff developed two structural model-based frameworks. The first one was the Debt, Investment, and Growth (DIG) model, which is described in Buffie et al. (2012), and the second one was an important extension of that first model to NAtural-Resource (DIGNAR) abundant countries, and is described in Melina et al. (2014). ${ }^{1}$ The DIG and DIGNAR models have a dynamic-stochastic-general-equilibrium (DSGE) structure, which facilitates the construction of internally consistent policy scenarios that can be used for debt sustainability analysis. In these scenarios, the linkages between public investment, growth, and debt, as well as the private sector response and fiscal policy reaction functions, are at the heart of the analysis. Recent extensions of the DSF by Fund and World Bank staff incorporate the investmentgrowth nexus, but in a partial equilibrium setting (IMF, 2017a).

\footnotetext{
${ }^{1}$ The published versions of these papers correspond to Zanna et al. (2019, forthcoming) and Melina et al. (2016).
} 
The development of the DIG and DIGNAR models follows the methodological approach of adapting DSGE models to undertake macroeconomic policy analysis in developing countries, which is discussed in Berg et al. (2015). As they argue, these models contain many rough approximations and shortcuts, and may not reflect all the complex macroeconomic mechanisms of LICs. However, they can be adapted to capture some of the specificities of these countries and help complement the large body of existing empirical and narrative work. The suggested approach, based on the DSGE literature, has some specific advantages for policy analysis.

The DSGE nature of the DIG and DIGNAR models help provide transparency, consistency, and the capability of quantifying macroeconomic effects to policy analysis. These models are transparent, since they make explicit all the assumptions about the structure of the economy, including those associated with the government and private sector behavior. They are also transparent about the transmission mechanism of policies, provided these explicit assumptions. Consistency, on the other hand, is inherent to their model structure. Macroeconomic variables evolve over time and are determined jointly in these models that highlight the role of shocks in driving the economy, as well as the feedback effects from policy to economic behavior and vice-versa. Moreover, like other DSGE frameworks, the DIG and DIGNAR models can help assess and estimate the effects of systematic policy changes by quantifying the net effect of forces operating on different parts of the economy. ${ }^{2}$

As transparent and consistent quantitative tools, the DIG and DIGNAR models can help organize macroeconomic thinking and policy discussions in developing countries. They help build intuition about how various economic features and policies come together and matter for simulated outcomes. They provide a vehicle for transparently producing alternative quantitative macroeconomic policy scenarios that can be compared systematically to inform decisions in a consistent manner. For example, they allow to incorporate empirical evidence on the efficiency of public investment (or its return) and assess its role in determining the riskiness of different borrowing strategies for ambitious and front loaded public investment plans.

The DIG and DIGNAR models are real dynamic open economy models with traded and nontraded sectors. The DIGNAR model also has a natural resource sector. Both models are Neoclassical — they assume flexible prices and perfectly competitive markets - and put together several crucial pieces to analyze debt sustainability in developing economies, with an emphasis on the linkages between public investment, growth, and debt accumulation.

These models put together three essential pieces for the policy analysis of public investment scaling-ups. First, the investment-growth nexus, whereby public investment increases can translate into more public capital and therefore more output. Capital accumulation, however,

\footnotetext{
${ }^{2}$ See the discussion on DSGE models in Christiano et al. (2018).
} 
is affected by inefficiencies in public investment and absorptive capacity constraints, capturing the challenges that LIC governments have faced historically in making productive investments. Second, the specification of fiscal policy reaction functions for different tax (and transfer) instruments that attempt to ensure debt sustainability. While grants and concessional borrowing are exogenously given, external commercial and domestic borrowing help finance public investment surges, with taxes and transfers responding to stabilize debt over time. DIGNAR also features a resource fund that acts as a fiscal buffer, given that withdrawals from such fund can be used to cover government productive spending. Third, the private sector response to policy actions. Increases in public investment and the associated fiscal adjustment can generate private sector crowding-in or crowding-out effects. While in the long run there is always crowding in, if the projects are good, in the transition, crowding out may dominate, especially if there is not enough foreign financing.

Figure 1: Country Applications of the DIG and DIGNAR Models.

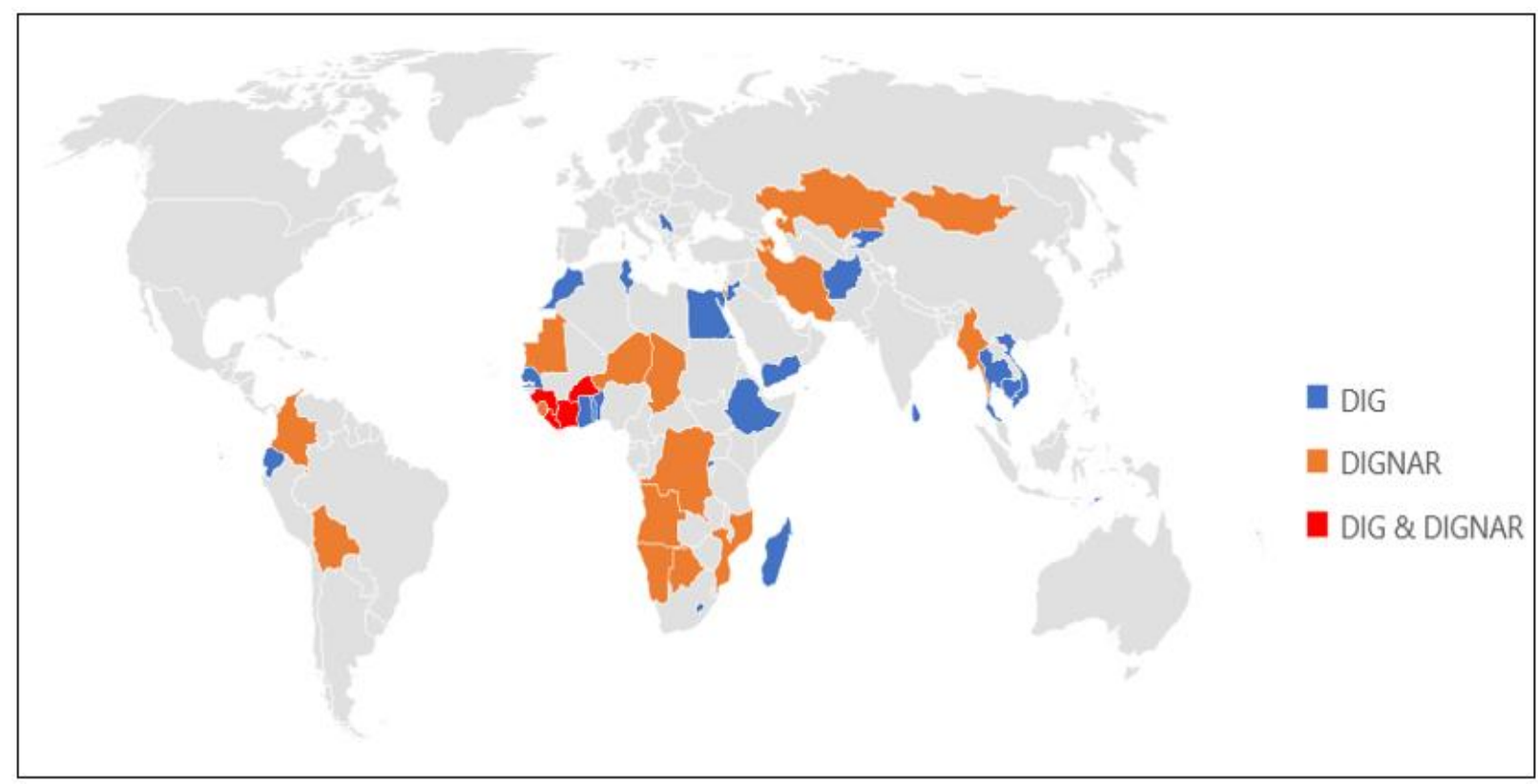

Source: Fund staff.

The analysis of over 65 DIG and DIGNAR country applications suggests that there are common policy lessons to be learnt across these cases (Figure1 and Appendix A). First, improving public investment efficiency and/or raising the rate of return of public projects boosts growth and lowers the risks associated with debt sustainability. Second, prudent and gradual public investment scaling-ups are preferable to aggressive front-loaded ones, in terms of private sector crowding-out effects, absorptive capacity constraints, and debt sustainability risks. Third, domestic revenue mobilization helps create fiscal space for investment scalingups, by effectively containing public debt surges and their later-on repayments. Fourth, aid smoothens fiscal adjustments associated with public investment increases and may lower the risks of unsustainable debt. And fifth, external savings mitigate Dutch disease macroeconomic effects and serve as fiscal buffers. 
Although qualitative in appearance, these lessons are also quantitative in nature, since they are derived from calibrating and simulating the models for each country-i.e., quantifying the macroeconomic effects for specific countries. In fact, the country applications showcase how the DIG and DIGNAR models can be used as quantitative tools, to answer questions such as the following: what is the output multiplier of increasing public investment? What are the quantitative effects on growth of improving the efficiency of public investment? How big are the macroeconomic costs associated with absorptive capacity constraints? What is the magnitude of the crowing-out effects on private demand, during public investment scalingups? By how much do these effects decrease with aid inflows? By how much can revenue mobilization help contain the burden of debt accumulation? among others.

There are several ways in which the approach of using the DIG and DIGNAR models for debt sustainability analysis complements the DSF at the Fund and the World Bank. In the latter, a baseline set of 20-year projections for borrowing, GDP growth, exports, and other key macroeconomic variables underpin the analysis of key debt ratios. These projections are part of a macro framework that reflects rich policy discussions and incorporate the country teams' judgement. DIG and DIGNAR can provide a consistency check for these projections to the extent that these models can be used to produce model-based projections, whose assumptions and main drivers are explicit, helping dissect and understand what is behind these projections. Moreover, these models allow to consistently produce and compare policy scenarios and get an independent sense of debt sustainability risks. In addition, by following the modern "fiscal space" approach to debt sustainability, which explicitly accounts for fiscal reaction functions (e.g., Bohn, 1998, and Ghosh et al. 2013), this model-based analysis brings new elements to debt sustainability assessments. Since the fiscal reaction functions in these frameworks are nonlinear, the macro stability and debt sustainability will depend on the size of the scaling up or of any of the shocks, among other factors, and not only on the parameters of the reaction function as is the case of linear policy functions.

The DIG and DIGNAR models were originally developed to address questions on the effects of public investment increases on growth and debt sustainability, but they were extended to other dimensions. The DIG model was extended to explicitly account for the energy sector in the analysis of ambitious energy investment plans in Ethiopia, Senegal, and Lesotho (Issoufou et al., 2014 and Andreolli and Abdychev, 2016). Further extensions were geared to the analysis of costs of operations and maintenance (Adam and Bevan, 2014); building climate resilient infrastructure (Marto et. al., 2017); the trade-offs between investing on economic and social infrastructure (Atolia et. al., 2017); and the trade-offs between public investment and security spending (Aslam et. al., 2013). In addition, the DIGNAR model was used to explore options to reduce poverty through direct cash transfers (Delechat et. al., 2015), and the design of a growth-friendly fiscal adjustment (IMF, 2016a).

The remainder of the paper is structured as follows. Section II provides a non-technical description of the main features of the DIG and DIGNAR models. Section III draws the main policy lessons from the body of country applications. Section IV presents several extensions 
and alternative uses of the models. Finally, Section V concludes. The full list of country applications with their associated web links is appended to the paper.

\section{MODEL DESCRIPTION}

In this section, we provide a general, non-technical description of the main features of the DIG and DIGNAR models. Both are real dynamic open economy models with traded and non-traded sectors and separate prices for exports and imports. DIGNAR also has a natural resource sector. They are Neoclassical models in the sense that there are no nominal rigidities and assume perfectly competitive markets with flexible prices for all goods and productive inputs. The absence of nominal rigidities is justified given the focus of the models on the medium to long term outcomes of public investment scale up plans ${ }^{3}$. The models are solved with a fully non-linear perfect foresight solution method, taking into account the anticipated nature of fiscal plans.

\section{Figure 2: Putting Together the Pieces.}

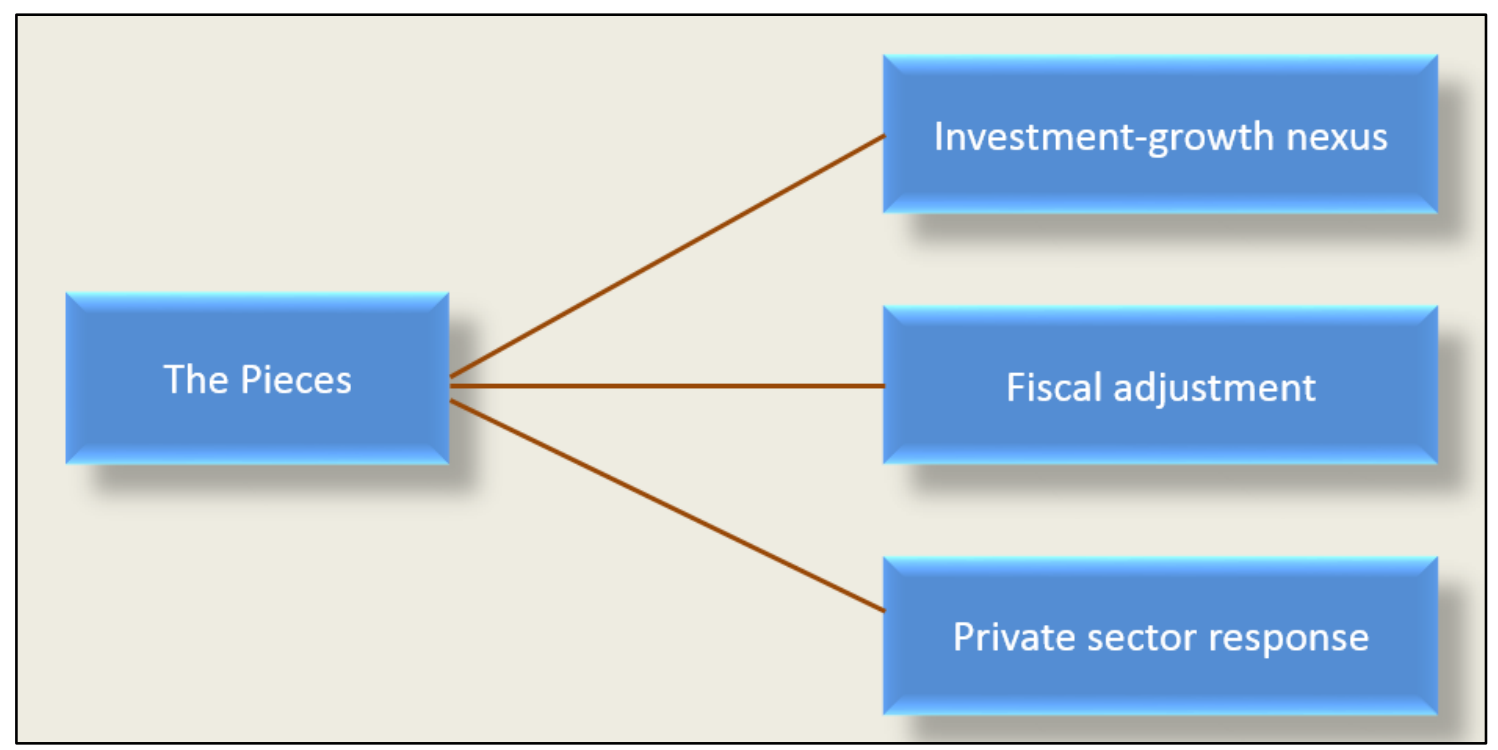

Source: Fund staff.

The DIG and DIGNAR models put together several crucial pieces that help capture the main mechanisms and policy issues of interest for debt sustainability analysis in LICs, particularly those associated with the linkages between public investment, growth, and debt. These

\footnotetext{
${ }^{3}$ An extension of the DIG model with labor market frictions is ongoing.
} 
crucial pieces comprise (i) the investment-growth nexus, (ii) the fiscal adjustment, and (iii) the private sector response (Figure 2). We proceed to elaborate on these pieces.

\section{A. The Investment-Growth Nexus.}

With respect to the public investment-growth nexus, the DIG and DIGNAR models account for high rates of return on public capital as well as significant inefficiencies in public investment and absorptive capacity constraints, which are pervasive in LICs. To capture this nexus, these models incorporate a neoclassical production function, which uses labor and private and public capital in each sector, as productive inputs. The technologies are assumed to be of the Cobb-Douglas type such as

$$
y_{t}=A_{t}\left(k_{t}^{g}\right)^{\psi}\left(k_{t}\right)^{\alpha}\left(l_{t}\right)^{1-\alpha},
$$

where $y_{t}$ is output, $A_{t}$ is total factor productivity, $k_{t}^{g}$ is public capital, $k_{t}$ is private capital, and $l_{t}$ is labor. The parameter $\psi$ of the production function determines the rate of return to installed public capital. Because public capital is productive, government spending can raise output directly and crowd in private investment. More specifically, public investment increases can translate into more public capital, which in turn raises the marginal productivity for private capital (and labor) and, through this channel, stimulates private investment.

There are also inefficiencies in public investment and absorptive capacity constraints, which capture the challenges that LIC governments have faced historically in making productive investments. Regarding the investment inefficiencies, both models reflect the fact that spending on public investment does not always imply an equivalent increase in the stock of public capital (Hulten, 1996, and Pritchett, 2000, among others). As such, the typical public capital accumulation equation is modified as follows:

$$
k_{t}^{g}=(1-\delta) k_{t-1}^{g}+\epsilon i_{t}^{g},
$$

where $i_{t}^{g}$ is public investment, $\delta$ is the constant depreciation rate, and $0 \leq \epsilon \leq 1$ is the efficiency parameter. Depending on the "efficiency" of public investment, some of the spending may be wasted or spent on poor (inframarginal) projects. As a result, one dollar of public investment does not necessarily translate into one dollar of productive public capital.

The IMF underscores the importance of improving public investment efficiency. With the help of the Fiscal Affairs Department, many countries undergo the Public Investment Management Assessment (PIMA), which helps them evaluate the strength of their public 
investment management practices (see IMF, 2008d, for details). ${ }^{4}$ At the end of this assessment, countries receive a score that, in several cases, has helped country teams calibrate the investment efficiency parameter in the DIG and DIGNAR models. ${ }^{5}$

The DIGNAR model also captures absorptive capacity constraints related to technical capacity in the investment process, which impact project selection, management, and implementation, and can have long lasting negative effects on growth (Esfahani and Ramirez, 2003, among others). The absorptive capacity constraints are incorporated by assuming that efficiency $\epsilon$ may depend negatively on the growth rate of public investment: if the growth rate of public investment exceeds its historical levels, then the efficiency of public investment is assumed to decline. Full algebraic details on this mechanism are explained by Melina et al. (2014).

\section{B. The Fiscal Adjustment.}

The models consider different government financing options and state explicitly the fiscal policy reactions for different tax (and transfer) instruments that attempt to ensure debt sustainability. As in other dynamic models that ensure consistency between stock and flows, the budget constraint of the government plays a central role:

$$
\begin{gathered}
\underbrace{s_{t} \Delta a_{t}+s_{t} \Delta d_{t}+\Delta b_{t}}_{\text {Borrowing }}-\underbrace{s_{t} \Delta f_{t}}_{\begin{array}{c}
\text { Resource } \\
\text { Fund } \\
\text { Accumulation }
\end{array}}=\underbrace{s_{t} r_{a, t-1} a_{t-1}+s_{t} r_{d, t-1} d_{, t-1}+r_{t-1} b_{t-1}}_{\begin{array}{c}
\text { Interest } \\
\text { Payments }
\end{array}} \\
-\underbrace{r_{f, t-1} s_{t} f_{t-1}}_{\begin{array}{c}
\text { Interest } \\
\text { Earnings }
\end{array}}+\underbrace{i_{t}^{g}+g_{t}}_{\text {Spending }}-\underbrace{\mathcal{A}_{t}}_{\text {Grants }}-\underbrace{\mathcal{R}_{t}}_{\begin{array}{c}
\text { Resource } \\
\text { Revenues }
\end{array}}-\underbrace{\sum_{j=1}^{\mathcal{R}_{\text {Tart }}} \tau_{j t} n_{j t}}_{\text {Taxes }},
\end{gathered}
$$

where $s_{t}$ is the real exchange rate; $\Delta a_{t}, \Delta d_{t}$, and $\Delta b_{t}$ are external commercial, external concessional, and domestic borrowing, respectively, with their corresponding real interest rates $r_{a, t}, r_{d, t}$, and $r_{t}$; changes in the resource fund are represented by $\Delta f_{t}$, whose stock earns an interest rate $r_{f, t}$; government spending corresponds to public investment $i_{t}^{g}$ and transfers/consumption spending $g_{t}$; revenues comprise grants $\mathcal{A}_{t}$, royalties from natural resources $\mathcal{R}_{t}$, and taxes on consumption and/or factor incomes, which are represented in a general form as $\tau_{j t} n_{j t}$ where $\tau_{j t}$ is the tax rate, and $n_{j t}$ represents consumption or any income from productive factors-e.g., labor income $w_{t} l_{t}$.

\footnotetext{
${ }^{4}$ As of February 2019, 51 countries had completed a PIMA, providing a basis to set a reform plan tailored to country needs

${ }^{5}$ There is, however, no linear mapping between PIMA scores and public investment efficiency, the way it is intended in the model. Any mapping is therefore an approximation.
} 
The fiscal analysis takes available grants and concessional borrowing as exogenously given. Since this borrowing is not sufficient to cover the also exogenous public investment scalingup plan, a fiscal gap arises. Absent any additional financing sources, the government drastically adjusts taxes and transfers to close the gap. In the most common and realistic scenarios, external commercial and domestic borrowing help finance the public investment surge, with taxes and transfers responding to stabilize debt levels over time.

In DIGNAR, withdrawals from a resource fund can be also considered as a financing source. This fund plays the role of a fiscal buffer: positive differences between revenue inflows (including natural resource revenue) and spending outflows (including investment expenditures) are saved, while negative differences imply that the fund is drawn down, subject to a minimum level of savings. When the fund reaches an exogenously given lower bound, one or more fiscal instruments react to close fiscal gaps either instantaneously or by temporarily allowing accumulation of public debt, like in DIG.

While the path of public investment is set exogenously by the user to produce alternative policy scenarios, the models incorporate fiscal rules for tax instruments (and transfers), while allowing for the imposition of feasibility constraints on the pace or level of these fiscal adjustments. These constraints potentially yield explosive debt trajectories. In general terms, the tax instruments $\tau_{j t}$ follow the non-linear fiscal rule

$$
\tau_{j t}=\operatorname{Min}\left\{\tau_{j}^{u}, \tau_{j t}^{r}\right\}
$$

where is $\tau_{j}^{u}$ is an exogenously imposed ceiling on tax $(\mathrm{j})$ adjustment, reflecting policy feasibility constraints, and

$$
\tau_{j t}^{r}=\tau_{j t-1}+\lambda_{\tau}\left(\tau_{j t}^{\text {target }}-\tau_{j t-1}\right)+\lambda_{x}\left(x_{t}-x_{t}^{\text {target }}\right)
$$

with $\lambda_{\tau}, \lambda_{x}>0$, and where $\tau_{j t}^{\text {target }}$ is the debt-stabilizing value for the tax instrument, $x_{t}$ is the debt-to-GDP ratio - it could be domestic and/or external commercial-, and $x_{t}^{\text {target }}$ is an exogenously given debt target. Similar rules apply to current expenditures or transfers with the imposition of floors. Particularly the presence of these thresholds makes resorting to nonlinear solution methods a necessity.

Given the instrument and debt targets, the reaction functions together with the budget constraint of the government embody the core policy dilemma. In response to ambitious public investment plans, fiscal adjustment is painful, especially when administered suddenly in large doses. The government would prefer therefore to phase-in tax increases (or current expenditure cuts) slowly. Since fiscal adjustment is gradual, then the increase in public investment generates a fiscal gap that can be covered by accumulating more domestic or external commercial debt — or by withdrawing from the resource fund, if possible, in the DIGNAR model. However, if the government moves too slowly-i.e., $\lambda_{\tau}$ and $\lambda_{x}$ are too 
low_ - or if the ceiling $\tau_{j}^{u}$ constrains adjustment too much, interest payments will rise faster than revenue, causing the debt to grow explosively. Therefore, large debt-financed increases in public investment become undeniably risky. The economy converges to a debt sustainable equilibrium only if policy makers win the race against time.

\section{The Private Sector Response.}

The DIG and DIGNAR models also incorporate the private sector response to policy actions. This is mostly related to private investment in both sectors and to private consumption. Investment is subject to real frictions such as adjustment costs. There is also limited access to international capital markets to capture financial market imperfections.

In both models, there is some heterogeneity regarding private consumption behavior. There are consumers who can smooth consumption because they have access to assets such as bonds and capital. There are also hand-to-mouth consumers who are forced to consume their income in every period. The presence of these consumers and distortionary taxes help break the Ricardian equivalence.

The response of the private sector to increases in public investment and to fiscal adjustment can be summarized in the associated crowding in and crowding out effects. With a public investment scaling up, more public capital is accumulated. This raises the marginal product of capital, inducing more private investment and therefore crowding in. On the other hand, when the government uses domestic resources to invest, these resources are not available for private investment and consumption. Tax increases or transfers reductions lower private consumption. Hence fiscal policy can also crowd out private investment and consumption. Which effects dominates - crowding in versus crowding out — depends on several factors. In the long run, there is always crowding in, if the projects are good. In the transition, crowding out may dominate, especially early on and if there is not enough foreign financing.

\section{Policy Lessons}

DIG and DIGNAR have complemented the debt sustainability analysis conducted at the Fund, by allowing staff to quantify, in a transparent and consistent manner, the macroeconomic effects of public investment increases, including on growth and debt accumulation. As mentioned in the introduction, transparency is reflected in these models by making explicit the assumptions and linkages between macro variables; while consistency is ensured, among others, by capturing the feedback effects from policy decisions to private sector responses, and vice-versa, in a general equilibrium set-up.

Consistency is also captured by the country-specific calibration of these models, as far as country data permits, as well as by repeatedly applying the same framework to the same country. This permits to analyze different policy questions while respecting the ceteris paribus assumption. For instance, when analyzing the growth payoffs of raising the rate of 
return of projects, staff can isolate the effects of this experiment, by using the same framework, changing only this rate of return, and keeping the rest of the policy assumptions and calibration constant. As such, DIG and DIGNAR serve as quantitative tools that can help improve policy analysis by allowing sensible and sound comparisons between baseline and alternative scenarios related to changes in policies or structural parameters.

Despite country-specific calibrations or policy experiments, the analysis of more than 65 DIG and DIGNAR applications suggests that there are common policy lessons across country cases:

1. Improving public investment efficiency and/or raising the rate of return of public project boosts growth and lowers the risks associated with debt sustainability.

2. $\quad$ Prudent and gradual public investment scaling-ups are preferable to aggressive front-loaded ones, in terms of private sector crowding-out effects, absorptive capacity constraints, and debt sustainability risks.

3. Domestic revenue mobilization helps create fiscal space for investment scaling-ups, by effectively containing public debt surges and their later-on repayments.

4. Aid smoothens fiscal adjustments associated with public investment scaling-ups and may lower the risks of unsustainable debt.

5. External savings mitigate the Dutch disease effects and serve as fiscal buffers.

We proceed to analyze each of these lessons, providing some country application examples. As we discussed these examples, we also illustrate how the DIG and DIGNAR models can be used to quantify the macroeconomic effects related to these lessons.

\section{A. Improving Public Investment Efficiency and/or Raising the Rate of Return of Public Projects Boosts Growth and Lowers the Risks of Debt Sustainability.}

Most country applications found that improving investment efficiency is key to reaping growth benefits of public investment scaling-ups, while minimizing the associated debt sustainability risks. Raising efficiency was perhaps (and still is!) one of the most important challenges that policymakers are faced with in LICs. The common view was that complementary efforts to improve the appraisal, selection, implementation, and evaluation of projects could increase efficiency and translate public investment into more public capital and higher growth. But if this were the case, by how much would growth increase due to improvements in efficiency? Or in the opposite case, by how much would growth be affected if efficiency deteriorates? And would there be any debt sustainability risks associated with such deterioration? The DIG and DIGNAR models helped provide quantitative answers to these questions. 
Figure 3: The Role of Improving Public Investment Efficiency.

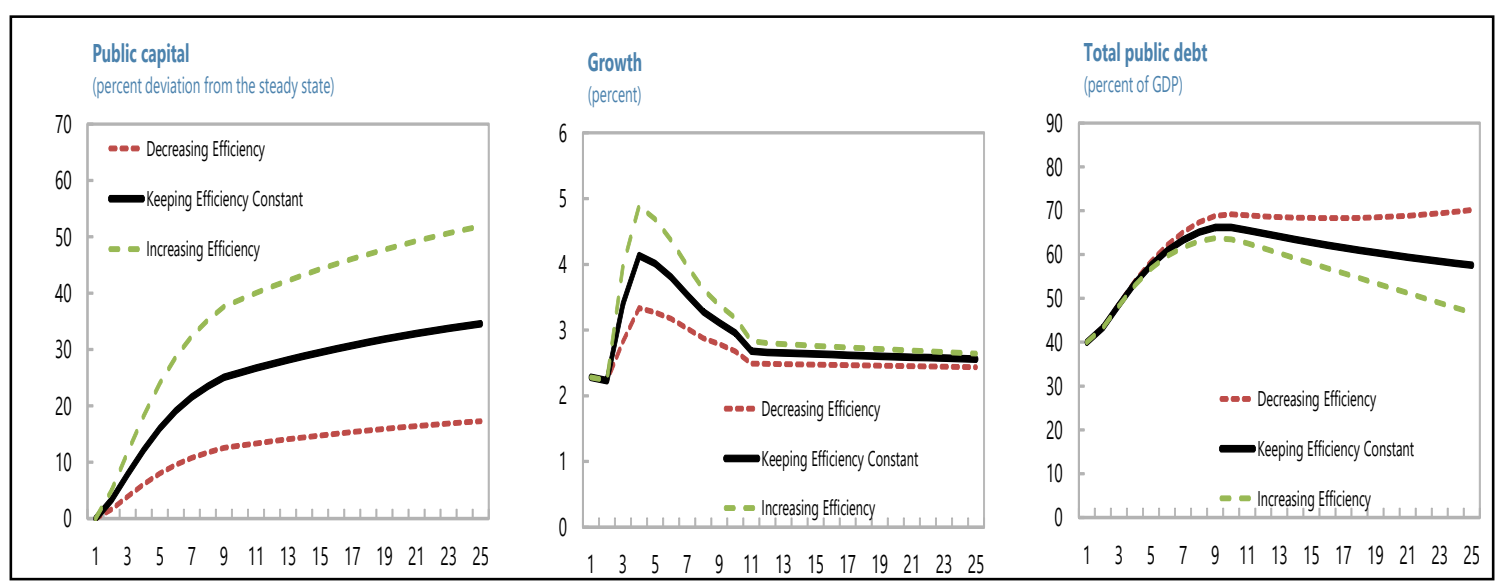

Source: DIG Application in the LIC Report (IMF, 2014a).

To illustrate the quantitative effects on growth and debt accumulation of increasing public investment while improving its efficiency, the DIG model was calibrated to an average LIC and simulated in IMF (2014a). This was a stylized version of the experiments conducted in several country applications. The calibration followed Buffie et al. (2012) where, in particular, the average LICs efficiency was set at 0.5 , in line with Pritchett (2000). The simulation results showed that a 10 -year average scaling-up of 4.5 percentage points of public investment to GDP coupled with improving efficiency from 0.5 to 0.75 could deliver a gain of 1.4 percentage points in per-capita GDP growth over a decade. By contrast, with a decline of efficiency from 0.5 to 0.25 , scaling-up plans would generate much smaller growth dividends; and if these plans were to be financed with more non-concessional borrowing, public debt could become unsustainable (Figure 3).

The efficiency experiments from the applications focused on the public investment effects when efficiency, in the country under analysis, was assumed to improve overtime. This experiment is not the same as comparing the effects in a high-efficiency country versus those in a low-efficiency country. For Cobb-Douglas production functions, like the ones in the DIG and DIGNAR models, high- and low-efficiency countries reap the same growth gain from the same additional public investment spending. This is the so-called invariance result of Berg et al. (2018).

Although seemingly puzzling, the invariance result of why the level of efficiency does not matter for growth, in a Cobb-Douglas world, has solid economic foundations. As Berg et al. explain in detail, the marginal contribution of an additional dollar of investment spending to output can be broken down into the product of the following two components: the amount of capital actually installed and the marginal productivity of that capital. Low public investment efficiency implies that less than a dollar of capital is installed. However, a country with permanently low efficiency has been installing less capital forever and consequently has a lower public capital stock. With the standard assumption of decreasing returns to any one factor of production, this implies a higher marginal product of public capital. These two 
components pull in opposite directions and have effects that perfectly offset with CobbDouglas production functions, making growth independent of the level of efficiency. ${ }^{6}$ What matters for growth gains is the increase in efficiency.

Figure 4: Better Project Selection Enhances the Return on Public Capital.

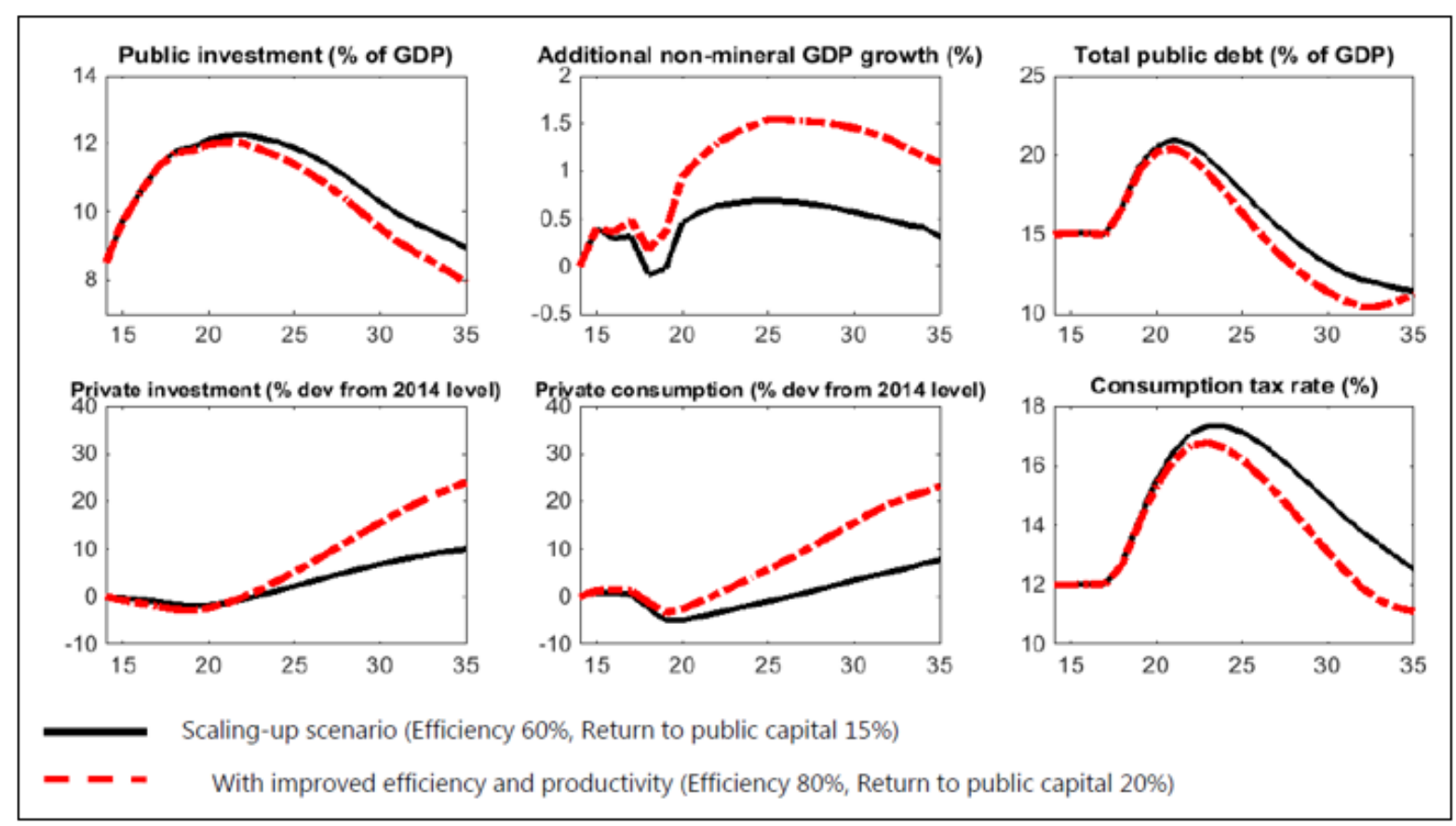

Source: DIGNAR application to Botswana (IMF, 2016b).

Country applications also investigated the role of the rate of return on public capital. The analysis of these applications acknowledged that one pervasive problem in developing countries, besides cost overruns, corruption, and other factors affecting the efficiency of public investment, was the lack of institutions that facilitate the careful appraisal of projects. This suggested that improvements in the selection of investment projects could increase the average real return on the public capital stock. A DIGNAR application to Botswana demonstrated the benefits from improving not only the investment efficiency, but also the return of public projects (IMF, 2016b).

The Botswana simulation results highlighted sustainable growth dividends from public investment reforms geared towards removing inefficiencies and prioritizing high-return

\footnotetext{
${ }^{6}$ Berg et al (2018) also show that, in the case of a CES technology, an increase in public investment raises growth more in the low-efficiency country when the elasticity of substitution between private and public capital is less than unity, suggesting an efficiency paradox. They also show the extent to which the invariance result and the efficiency paradox can be generalized in the context of the endogenous growth models formulated by Lucas (1988) and Barro (1990).
} 
projects (Figure 4). The reforms were assumed to improve the efficiency of public investment from 60 to 80 percent over a period of ten years, together with an increase in the annual net return on public capital from 15 to 20 percent, a range of values reflecting the existing empirical evidence. Such broad-based reforms could magnify the positive macroeconomic impact of a gradual scaling up of public investment in infrastructure. The simulations found that a gradual process that raised investment in infrastructure up to 12 percent of GDP, over the medium-term, would increase the growth rate of non-mineral real GDP, on average, by an additional 1.2 percentage points per year, compared to the baseline without reforms. Private investment and consumption, in this case, would be also significantly higher, while the burden of debt would be smaller.

\section{B. Prudent and Gradual Public Investment Scaling-Ups are Preferable to Aggressive Front-Loaded Ones.}

The ability of governments to effectively carry out public investment is largely a function of their capabilities to implement this investment. Their ability depends on the supply of skilled administrators and adequate institutional capacity for planning and oversight, among others. Absent such capabilities, governments confront coordination problems or supply bottlenecks during the implementation of large public investment projects, which are commonly referred to as absorptive capacity constraints. Often, these constraints are manifested as declines in the efficiency of government investment or as pervasive costs and schedule overruns, which affect government budgets and play a critical role in determining the final impact of public investment on growth.

Covering the costs of public investment scaling-ups through fiscal adjustment- higher taxes or cuts of transfers - has clear implications for private demand. In this case, resources are shifted away from the private sector to the public sector, crowding out private consumption and investment. However, public investment also augments the productivity of private inputs via the accumulation of public capital; and, through this channel, it may generate an increase in national income that may more than offset the absorption of private resources by the government. Hence, public investment may also crowd in private consumption and investment. What effects dominates - crowding out versus crowding in — as well as the size of the final impact on the private sector - e.g., the magnitude of the crowding out — depend on several conditions. These include the public investment efficiency, the rate of return on public capital, and the size and execution pace of the public investment plan, among others.

Government borrowing to finance public investment scaling-ups can lead to substantial build-ups of public debt. As with fiscal adjustment, domestic borrowing implies a transfer of private resources to the government, crowding out private demand. External commercial borrowing, on the other hand, may help smooth this negative adjustment of the private sector, as resources come from abroad. But both types of borrowing-domestic and external commercial - may cause substantial increases in public debt-to-GDP ratios, to levels 
associated with high risks of debt distress, especially when financing large and front-loaded public investment plans. To avert the materialization of such risks, the government may be forced to implement, sooner or later, drastic fiscal adjustments which again will impact negatively the private sector.

Most of the DIG and DIGNAR country applications showed that large and front-loaded public investment scaling-ups could seriously increase the macro-fiscal vulnerabilities of a country. In the country simulations, very ambitious and front-loaded investment plans significantly crowded out private demand, raised questions about the underlying ability of the economy to effectively absorb high resource flows, and posed fiscal and debt sustainability challenges. As a result, these applications found that moderate and gradual scaling-ups are preferable to aggressive and front-loaded ones, when looking at crowding-out effects, absorptive capacity constraints, and debt sustainability, as criteria. We elaborate on these results.

\section{Figure 5: Crowding-Out Effects on Private Demand of a Prudent Versus an Aggressive Public Investment Scaling-Up.}

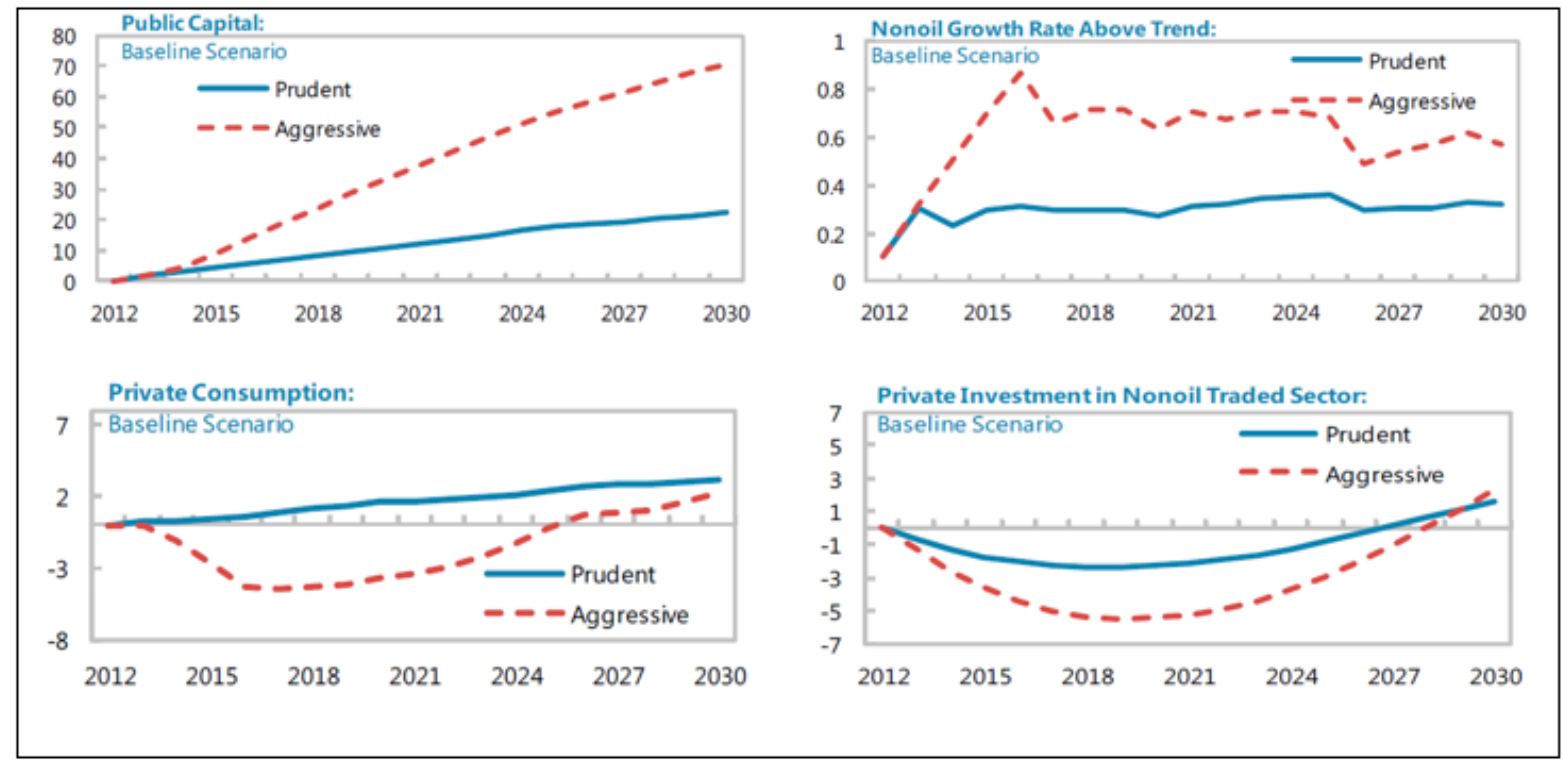

Source: DIGNAR application to Kazakhstan (IMF, 2013a).

1. Illustrating the crowding out of private demand. The country applications revealed that with high rates of return on public capital and improvements in the efficiency of public investment, private investment and consumption were usually crowded in, during the medium to long run, by an increase in public investment. In the short run, however, there was private demand crowding out, because taxes (with or without delays) needed to adjust to keep public debt sustainable. This fiscal adjustment, together with higher interest rates, affected private demand decisions negatively. The crowding-out effect was more pronounced if the government resorted to domestic borrowing. In addition, in country applications with 
aggressive public investment scaling-ups - featuring a pronounced initial overshooting of infrastructure spending - the crowding-out effect on the private sector was exacerbated. The application of DIGNAR to Kazakhstan showcased the presence and magnitude of private sector crowding-out effects (IMF, 2013a). Two public investment scaling-up scenarios were considered: a prudent scenario and an aggressive scenario, where public investment was raised, on average, to 6.4 percent and to 12 percent of GDP, respectively. The simulations showed that an aggressive scaling-up could boost the level of public capital and non-oil growth, relative to the prudent scenario (Figure 5). Non-oil growth, for instance, could be higher in the aggressive scenario by more than 0.2 percentage points, on average, in the next decade. However, the aggressive scenario could also lead to a stronger crowding-out effect on private consumption and on investment in the tradable sector. In the next decade, consumption could fall by up to 5 percent in the aggressive scenario, which starkly contrasted with the persistent increase featured by the prudent scenario.

Figure 6: The Role of Absorptive Capacity Constraints on the Effects of a Gradual Versus an Aggressive Public Investment Scaling-Up.

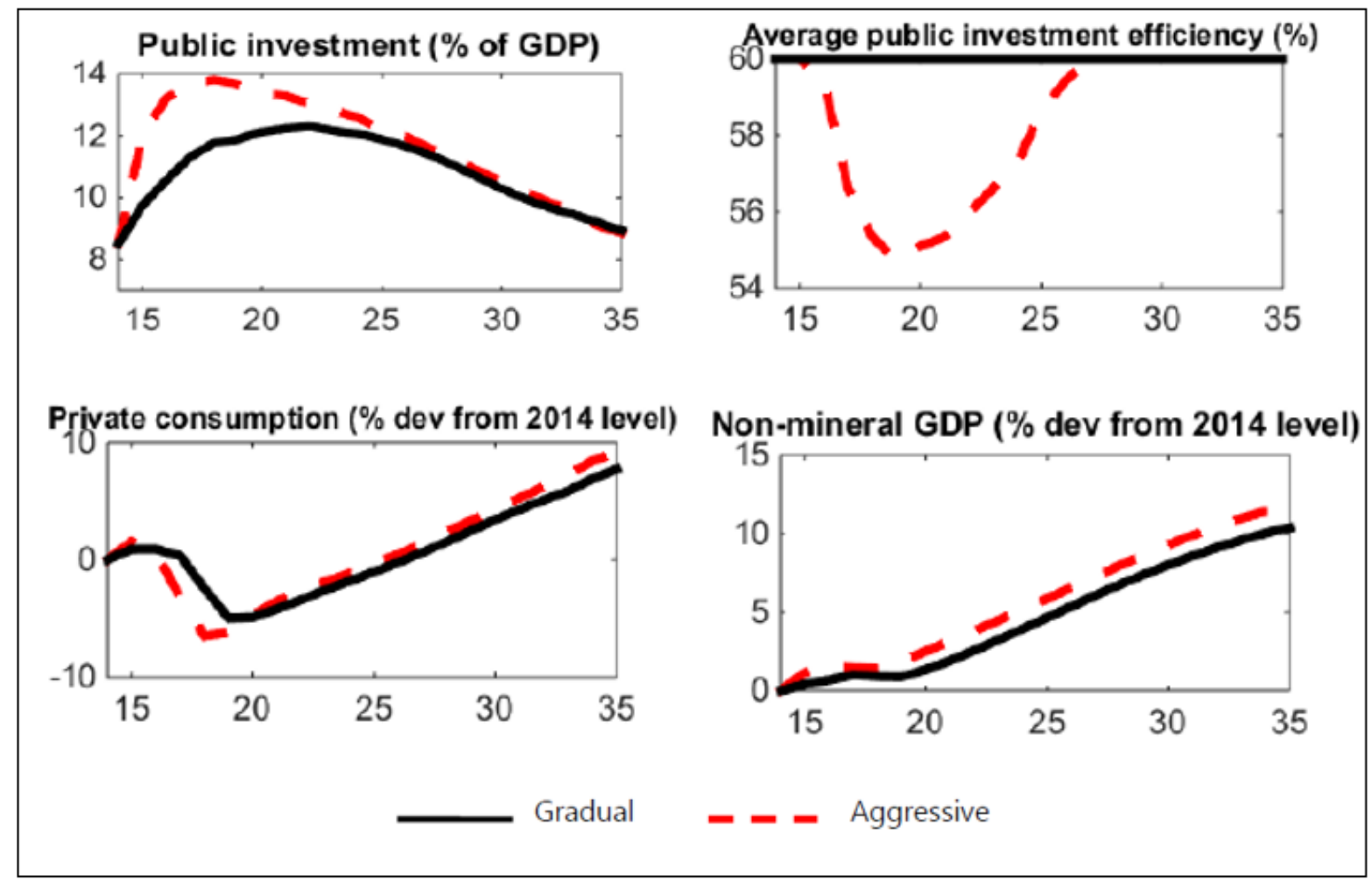

Source: DIGNAR application to Botswana (IMF, 2016b).

2. Investigating the role of absorptive capacity constraints. As explained in Section II, the efficiency of public investment is endogenized, in DIGNAR, as a decreasing function of the pace of the public investment scaling-up. This mechanism captures the fact that there are absorptive capacity constraints on the level of public investment that the economy can retain. If the pace of the investment scaling-up is too fast, these constraints are more likely to bind, 
and investment efficiency is likely to drop. Hence a bigger part of investment expenditures will be wasted. This mechanism, like the crowding-out effects channel, also suggests that prudent scaling-ups may be preferable. The Botswana application investigated the role of absorptive capacity constraints on the macroeconomic effects of a public investment scalingup. Two scenarios for such scaling-up, gradual versus aggressive, were considered (IMF, $2016 \mathrm{~b}$ ). In the gradual approach, spending on growth-enhancing investment projects were slowly increased, from roughly 8 percent to 12 percent of GDP, over the short to medium run (Figure 6). In the aggressive approach, public investment increased faster, reaching about 14 percent of GDP in the short run. Despite the faster pace of investment, the latter approach only delivered a slightly larger build-up of public capital and non-mineral output, relative to the gradual approach. This was partly explained by the fact that, given absorptive capacity constraints, the aggressive approach led to a decrease in public investment efficiency from 0.6 to 0.55 . In addition, this aggressive approach implied higher financing needs - tax rate hike and more borrowing - which translated into a more pronounced decline of private consumption compared to the drop of consumption in the gradual scenario.

Some country applications estimated the cost of absorptive capacity constraints, in terms of the output multiplier, using the DIGNAR model. Consider, for example, the CEMAC application that compared the macroeconomic outcomes of saving an oil windfall in a Sovereign Wealth Fund (SWF) versus investing it all in public capital (Berg et. al., 2013). When expenditure levels surpassed 60 percent of their historical level, absorptive capacity constraints were binding, and investment efficiency fell from 0.5 to 0.35 . The cost associated with the absorptive capacity constraints was computed comparing the present-value of the cumulative non-oil output multiplier for public investment. Under the all-investing approach, the cumulative non-oil output multiplier was 0.41 , when absorptive capacity constraints were biding. In the absence of absorptive capacity constraints, the multiplier was 0.64 . This implies nontrivial output loss because of absorptive capacity constraints, as they induced investment inefficiencies. ${ }^{7}$

3. Illustrating the effects on public debt sustainability. A sharp increase in public investment financed by external commercial borrowing may lead public debt to dangerous levels, especially in the face of negative shocks. This may also require painful fiscal adjustments in the medium term. To illustrate these dangerous effects of an aggressive public investment scaling-up consider, for instance, the DIGNAR application to Mozambique (IMF, $2013 b$ ). This country was expected to begin production of liquified natural gas (LNG) around 2020. By 2028 exports were expected to peak at 30 percent of non-oil GDP, while fiscal revenue from the sector would bring in as much as 9 percent of non-oil GDP.

The analysis of three alternative public investment scenarios in the Mozambique's simulations revealed that aggressive and front-loaded scaling-ups may increase the risk of debt distress (Figure 7). The application considered the following approaches. A conservative approach, where government investment would increase only in the years when the LNG

\footnotetext{
${ }^{7}$ See Figure 1 in Berg, et al. (2013).
} 
production was projected to start, which would imply neither fiscal adjustment nor debt accumulation. A gradual approach that would anticipate some of the LNG revenue, covering the rest of the investment plan with borrowing. As a result, public debt would rise to sustainable levels in the medium term, requiring only a small fiscal adjustment. And an aggressive approach, which would fully anticipate future LNG revenues and increase public investment spending massively early on. The aggressive scaling-up would imply a much bigger build-up of public debt, reaching levels above 70 percent of GDP, and a more painful fiscal adjustment, making the economy very vulnerable. In fact, as explained below, simulations under an adverse scenario of 80 percent lower LNG output and decline in prices showed that public debt would become unsustainable (explosive) with this aggressive approach.

Figure 7: Public Debt Effects of Gradual vs Aggressive Public Investment Scaling-Up.

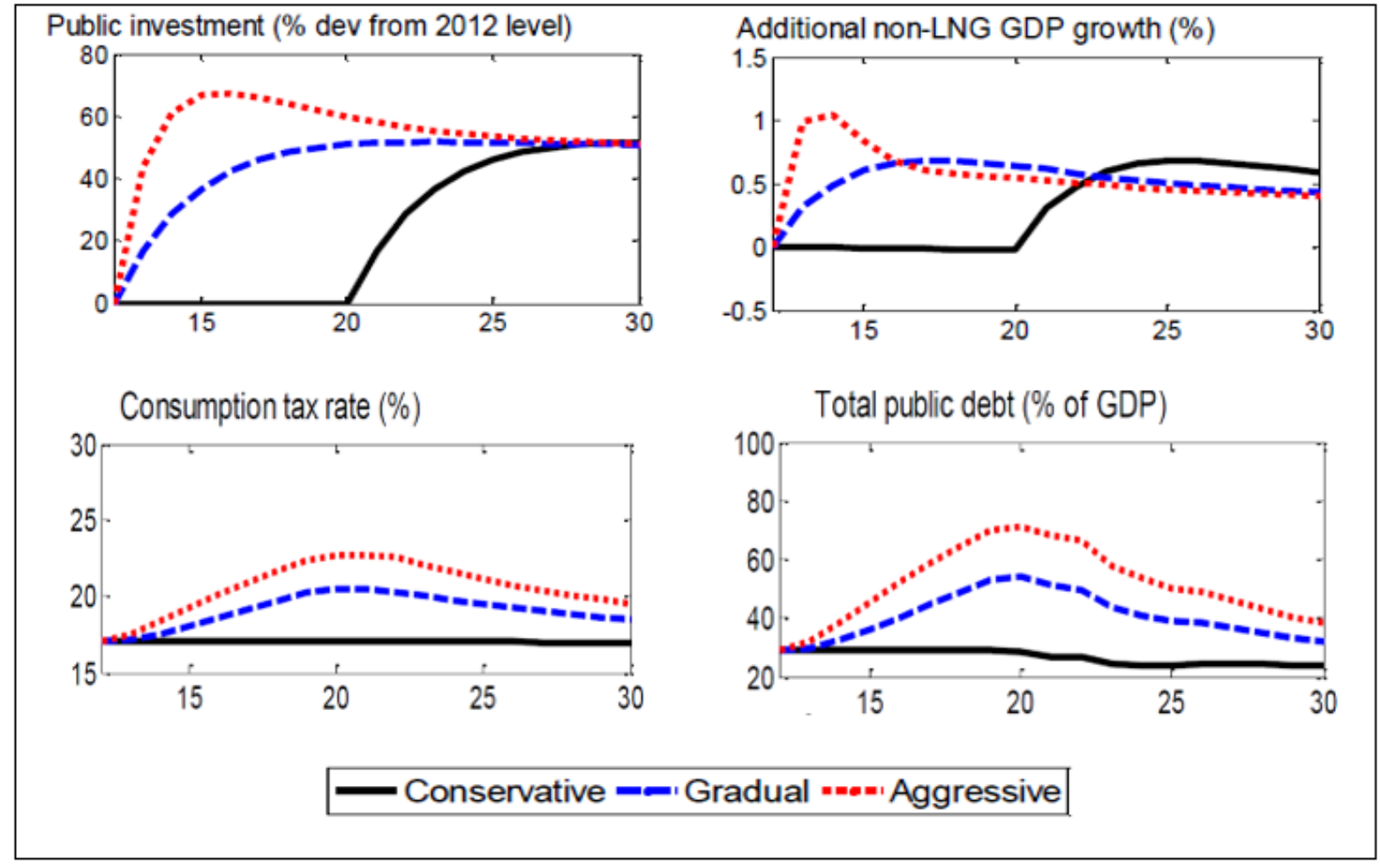

Source: DIGNAR application to Mozambique (IMF, 2013b).

\section{Domestic Revenue Mobilization Helps Create Fiscal Space for Investment Scaling- Ups, by Containing Public Debt Surges and their Repayments.}

The macroeconomic impact of public investment scaling-ups often depends on the strength of complementary reforms. One of these reforms corresponds to mobilizing domestic revenues, which helps contain public debt surges, during the scaling-up, and their principal 
and interest repayments later on. These reforms should be a priority in many LICs. SubSaharan African (SSA) economies, for instance, need to substantially raise revenues to support their fiscal-consolidation, debt-reduction, and diversification strategies. Although IMF (2018b) documents a gradual improvement in revenue mobilization over the past three decades, the average revenue-to-GDP ratio in SSA countries is still lower than in other regions of the world.

For developing natural resource-rich countries, revenue mobilization also plays a crucial role, given the price volatility stemming from the commodity cycle in recent years. In these countries, improved tax administration, a broader tax base, prioritization of current expenditures and reduction of subsidies - e.g. on fuel products - may help mitigate the effect of reduced natural resource-based government revenues on fiscal balances and sovereign risk premia. The DIGNAR model was applied to CEMAC, a natural resource-rich region, to analyze the role of revenue mobilization in the face of the recent drop in commodity prices (IMF, 2018b).

The application to the CEMAC region showed that increases in non-oil tax revenues could create fiscal space for scaling up public investment, while reducing debt pressures (Figure 8). Raising the VAT rate would induce a non-oil GDP fall, on impact, which is in line with the empirical literature on short-term fiscal multipliers. At the same time, debt would taper off. In the medium run, non-oil GDP would recover, driven by higher private investment and net exports. The increase in the VAT rate could also affect negatively consumption of poor consumers (HTM), because of their larger marginal propensity to consume.

To mitigate the negative effects on poor consumers, as well as on non-oil GDP, VAT increases could be supplemented with targeted cash transfers or with increases in public investment. In other words, domestic revenue mobilization could create fiscal space to be used for public investment or social purposes. When used for public investment, the CEMAC simulations showed that this strategy could have positive effects on growth and private investment, offsetting some of the negative effects exerted by the increase in taxes. Moreover, because of the revenue mobilization, public debt would decrease, helping with the medium-term prospects for debt sustainability as principal and interest repayments would decline. 
Figure 8: The Macroeconomic Effects of Tax Reforms.

Change in non-oil tax revenue

( $\%$ of GDP)

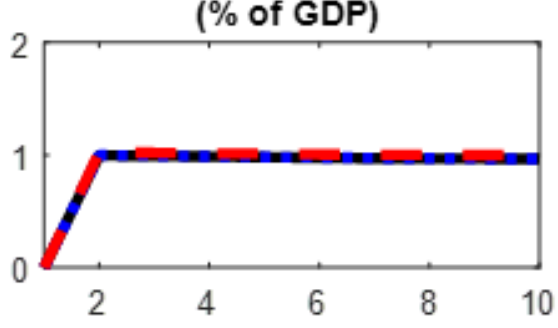

[A] Consumption - HTM

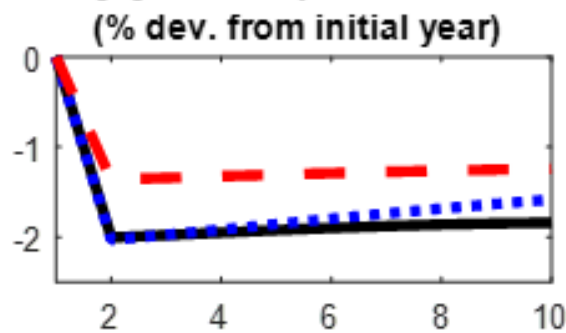

Difference in consumption changes [A]-[B]
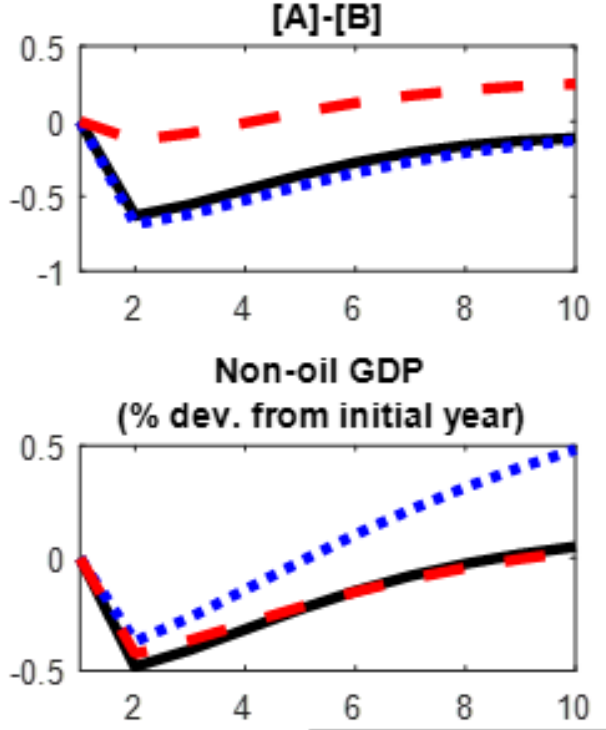

Private consumption

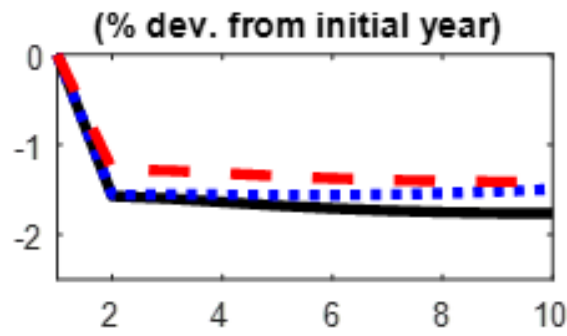

[B] Consumption - OPT

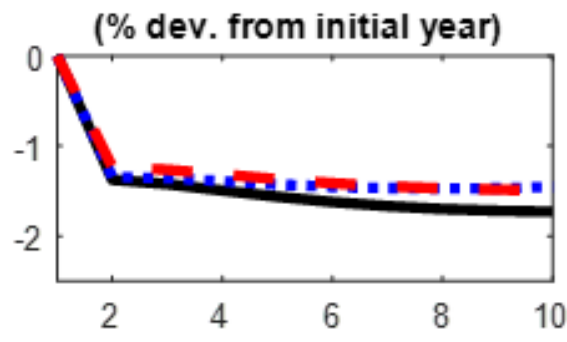

Private investment

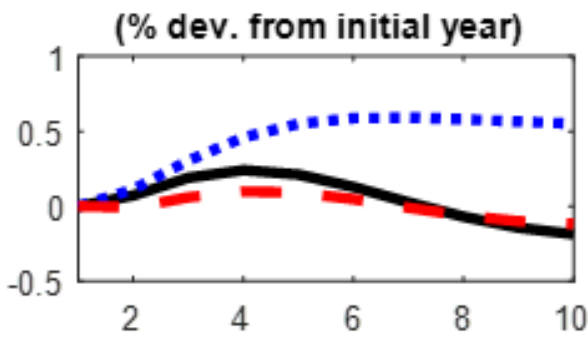

Change in total public debt (\% of GDP)

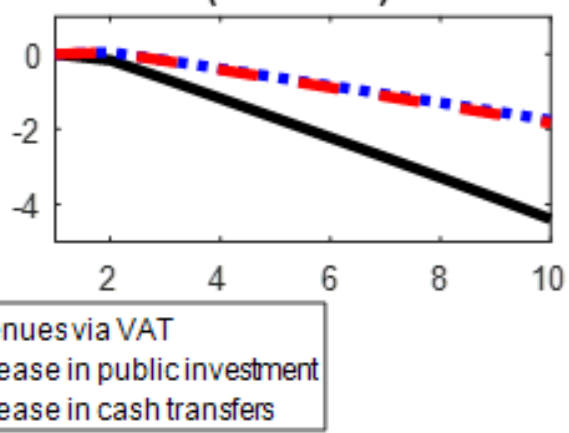

Source: DIGNAR application to CEMAC (IMF, 2018b). 


\section{Aid Smoothens Fiscal Adjustments Associated with Public Investment Increases and may Lower the Risks of Unsustainable Debt.}

Both DIG and DIGNAR feature foreign aid in the form of concessional loans and grants that affect the government budget constraint. While grants simply represent transfers from external donors that the government does not have to pay back, concessional loans extended by official creditors are characterized by a very low interest rate. Some country applications included grant financing as part of the simulation exercise. One example is the application of DIG to Serbia, which featured limited fiscal space, elevated levels of debt, and significant infrastructure gaps (IMF, 2017b). In that application, several policy scenarios were compared for financing public investment scaling-ups, including domestic borrowing, external commercial borrowing, and aid financing - 50 percent of grants and 50 percent of concessional loans.

Figure 9: Public Investment Scaling-Ups Under Different Financing Schemes.

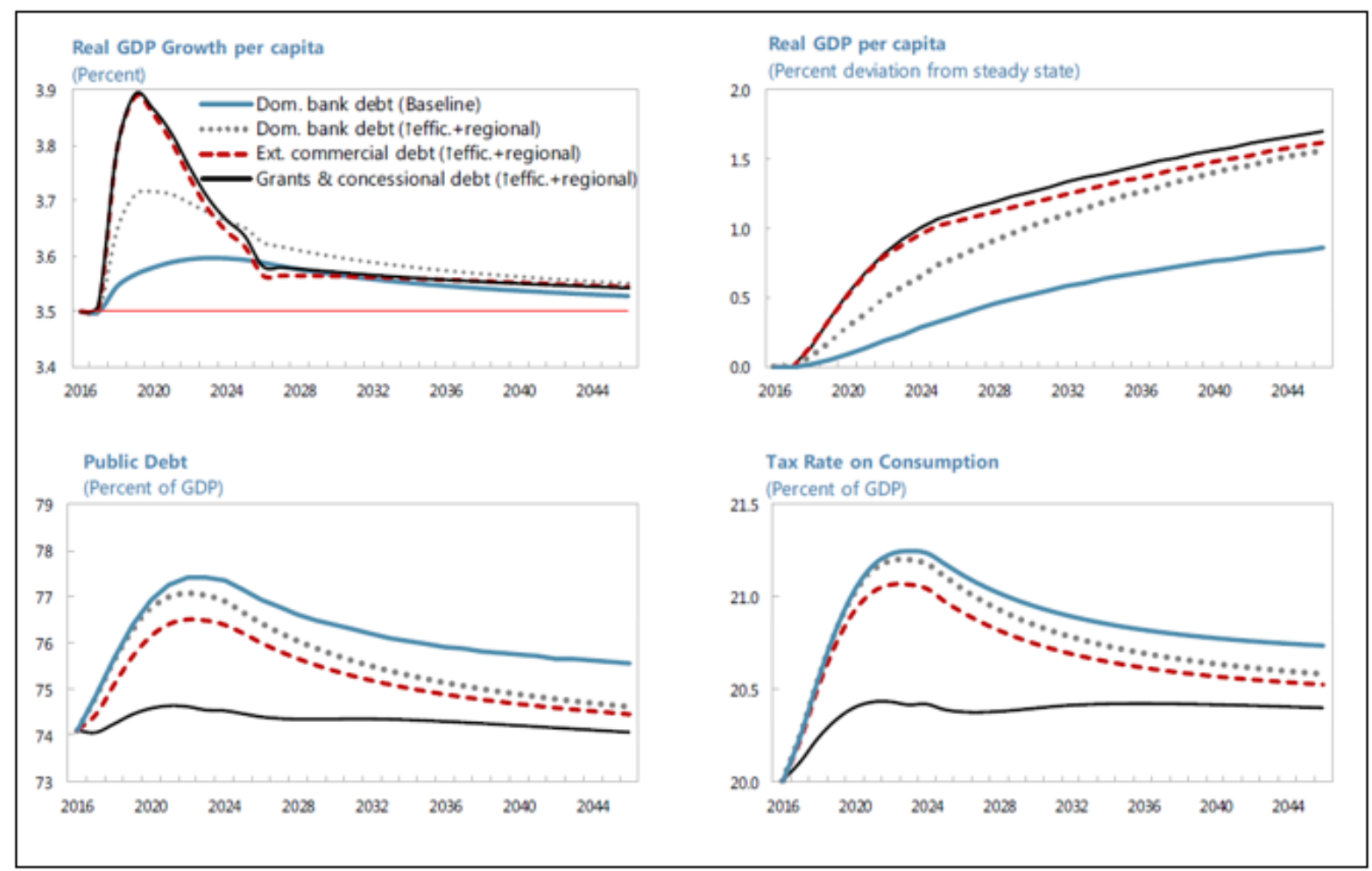

Source: DIG Application to Serbia (IMF, 2017b).

The DIG model simulations for Serbia underscored several advantages of aid financing relative to other non-concessional financing strategies, including easing fiscal adjustments and debt stabilization (Figure 9). Aid financing would eliminate the need for painful fiscal adjustments - substantial tax hikes or current spending cuts - leading to higher real GDP growth. Moreover, the grant/concessional financing coupled with higher real GDP growth 
rates would keep public debt stable. In the first decade and relative to non-concessional borrowing strategies, aid financing could imply lower tax rates on consumption and bigger real GDP growth rates by about 1 and 0.2 percentage points, respectively. Also, in contrast to non-concessional financing, aid would have an almost negligible impact on debt-to-GDP ratios, which was crucial in the case of Serbia, given the observed high levels of those ratios.

In the 2016 WEO application of DIGNAR, concessional loans were also found to help with fiscal consolidation and debt stabilization, in the context of low commodity prices (IMF, 2016c). Model simulations suggested that commodity-exporting LICs could face lower growth rates and rapid surges in public debt - about 28 percentage points of GDP in 3 years - given the declines in government oil-related revenues. Against this background, improving revenue mobilization, through better tax administration and a broader tax base, as well as measures reducing current expenditures, could help mitigate the effects of reduced oil-related revenues on fiscal balances. In addition, concessional financing could help address the remaining fiscal gap and contain increases in the interest burden and sovereign risk premia, helping stabilize public debt over the medium term. According to the simulations, for an average oil-exporting LIC, improvements in tax collection of 20 percent in tandem with additional concessional financing of 5 percent of GDP, could significantly slowdown public debt accumulation, and stabilize debt-to-GDP ratios at around 45 percent in the medium term (Figure 10).

Figure 10: The Role of Concessional Financing in Smoothing Fiscal Consolidation and Stabilizing Debt.

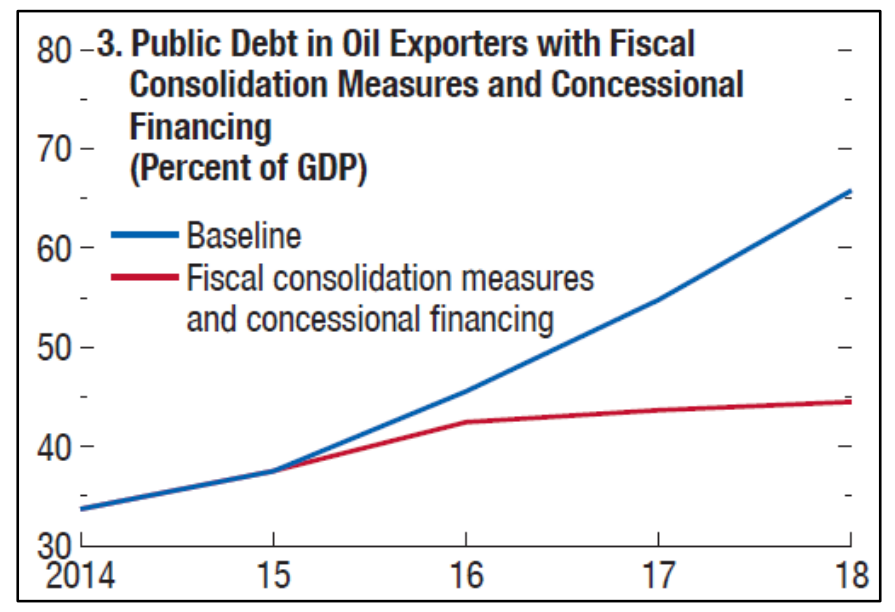

Source: DIGNAR application to commodity-exporting LICs (IMF, 2016c). 


\section{E. External Savings Help Mitigate Dutch Disease Effects and Serve as Fiscal Buffers.}

In the DIGNAR framework, part of the government revenues from natural resources can be saved in a fund abroad in the form of sovereign wealth fund. The saved amount is the portion of natural resource revenues that are not invested in public infrastructure projects. By saving this portion, the government can help mitigate Dutch disease effects - real appreciation and productivity losses in the tradable sector-associated with the inflow of foreign currency from exports of natural resources. Saving part of the natural resource revenues also contributes to building fiscal buffers, which can be used in rainy days-e.g., when the natural resource-rich economy is hit by negative commodity price shocks.

The DIGNAR application to Mozambique illustrated how, by saving in a resource fund, the government could counteract Dutch disease effects and create fiscal buffers (IMF, 2013b). As mentioned above, the analysis considered three public investment approaches, depending on the pace for increasing investment, namely, a conservative, a gradual, and an aggressive approach. In addition, the application featured a baseline and an adverse natural resource scenario. Under the adverse scenario, LNG production and prices were assumed to be lower than projected, generating a smaller revenue for the government and therefore savings, for a given public investment path.

Mozambique's simulations showed that an aggressive public investment approach could cause more pronounced Dutch disease effects relative to the other investment approaches (Figure 11). This aggressive approach would induce a more significant appreciation of the real exchange rate, under the baseline scenario - e.g., by year 4, it could induce appreciation twice as big as the one associated with the gradual approach. This bigger real exchange rate decline would translate into a relatively lower output in the traded sector, which would exacerbate productivity losses in that sector. As a result, under the aggressive scenario, the traded sector would decrease by much more than in the gradual scenario. Given the magnitude of the public investment scaling-up, these aggravated Dutch disease effects were driven by less public savings under the aggressive scenario than under other approaches.

The DIGNAR application to Mozambique also revealed how external savings could create fiscal buffers to help ensure debt sustainability during bad times. Because of the adverse scenario shocks to LNG output and price, as well as the size of the public investment scalingup, the government could only save in the fund with the conservative approach. This would create substantial fiscal buffers that could be used to smooth the economy's macroeconomic and fiscal adjustment, if the adverse conditions were to materialize. In fact, the country simulations showed that, under the conservative approach and adverse scenario, public debt builds up and tax increases would be approximately the same, in magnitude, as those from the baseline scenario. In contrast, under the aggressive approach and adverse scenario, there would be no fund savings - and related fiscal buffers - which would set public debt on an unsustainable path. 
Figure 11: The Role of External Savings.

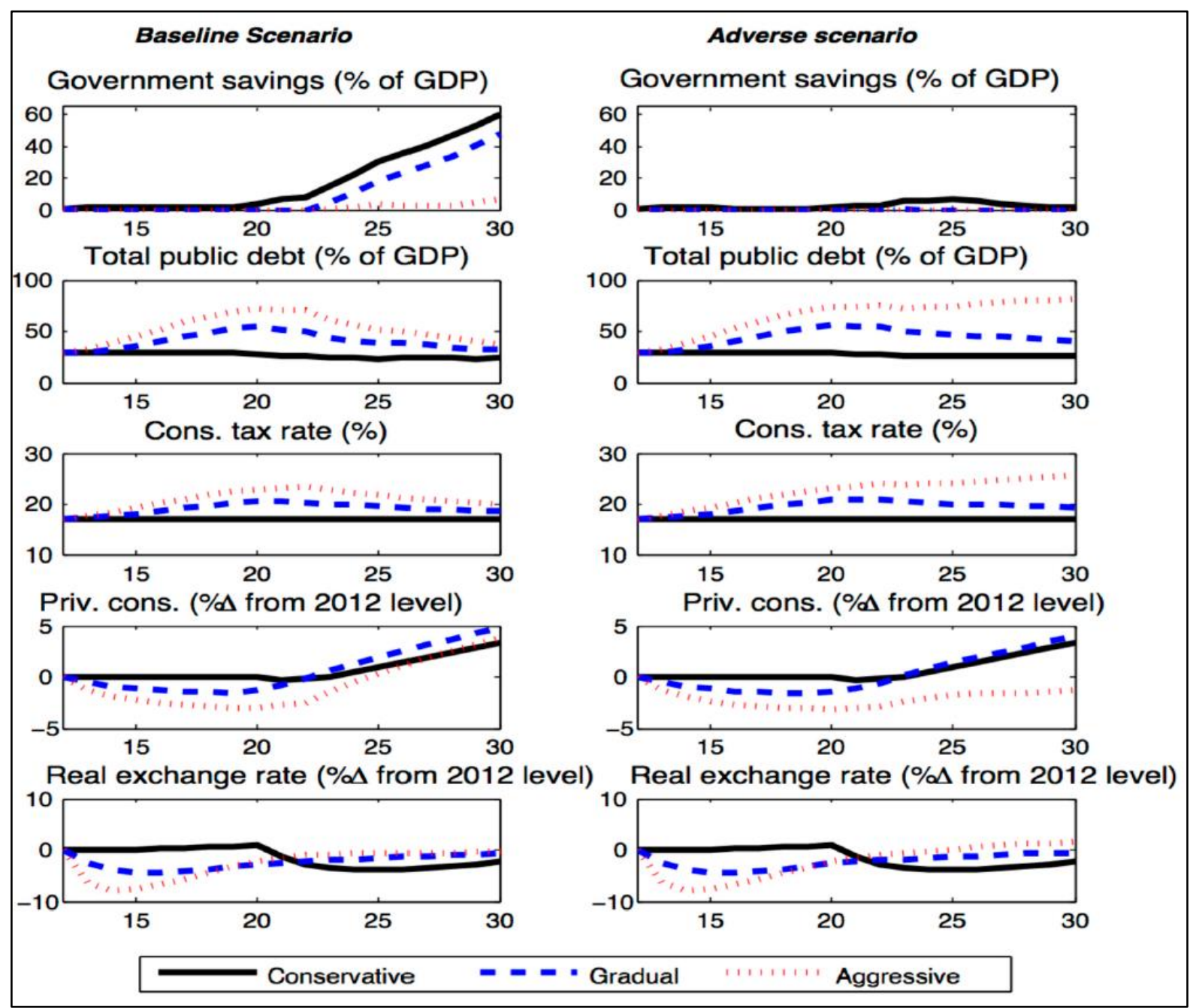

Source: DIGNAR application to Mozambique (IMF, 2013b).

\section{EXTENSIONS AND ALternative USES}

\section{A. Introducing an Energy Sector.}

For the Ethiopia's application, the DIG model was extended in several dimensions, including investing in an energy sector (IMF, 2014b). These dimensions comprised (i) a state-owned energy sector that would export electricity to neighboring countries and sell to firms and households at controlled, low prices-i.e., below shadow prices - and (ii) a state-owned banking sector that would fix interest rates and lend a large fraction of deposits to the public sector. The model and the investment program were calibrated to capture key characteristics of Ethiopia's development plan, including a highly favorable baseline with high rates of return to infrastructure ( 20 percent) and energy ( 30 percent), as well as large efficiency gains from the construction of the Renaissance dam. The stock of infrastructure would double in 
the long run, while energy investment and the efficiency gains from the Renaissance Dam would increase total energy supply four-fold (300 percent) at the 10-year horizon. The gap between investment outlays and concessional loans was assumed to be covered by a combination of fiscal adjustment and either additional borrowing from the domestic banking system or additional external commercial borrowing.

The Ethiopia's model simulations showed that reliance on domestic bank borrowing would require substantial fiscal and private sector adjustment to prevent macroeconomic instability (Figure 12). In the first 5 years, transfers would need to be cut by more than 5 percent of GDP; private investment would decline by more than 10 percent, relative to its historical levels; and inflation could sharply increase above 10 percent. By contrast, external commercial borrowing would allow public investment to increase without cuts in recurrent expenditures, temporary crowding-out effects on private investment, and sharp increases in inflation. However, these gains would have to be balanced against the risks associated with significant increases in the ratio of total external public debt, which could reach 50 percent of GDP. Increases in energy prices and slower public investment scaling-ups were also analyzed, showing that doubling energy prices charged to firms or increasing tax revenues, by about 1 percent of GDP, could induce large and dramatic reductions in the growth of external debt.

Figure 12: External Commercial Borrowing and Bank Borrowing in the DIG Model with an Energy Sector.
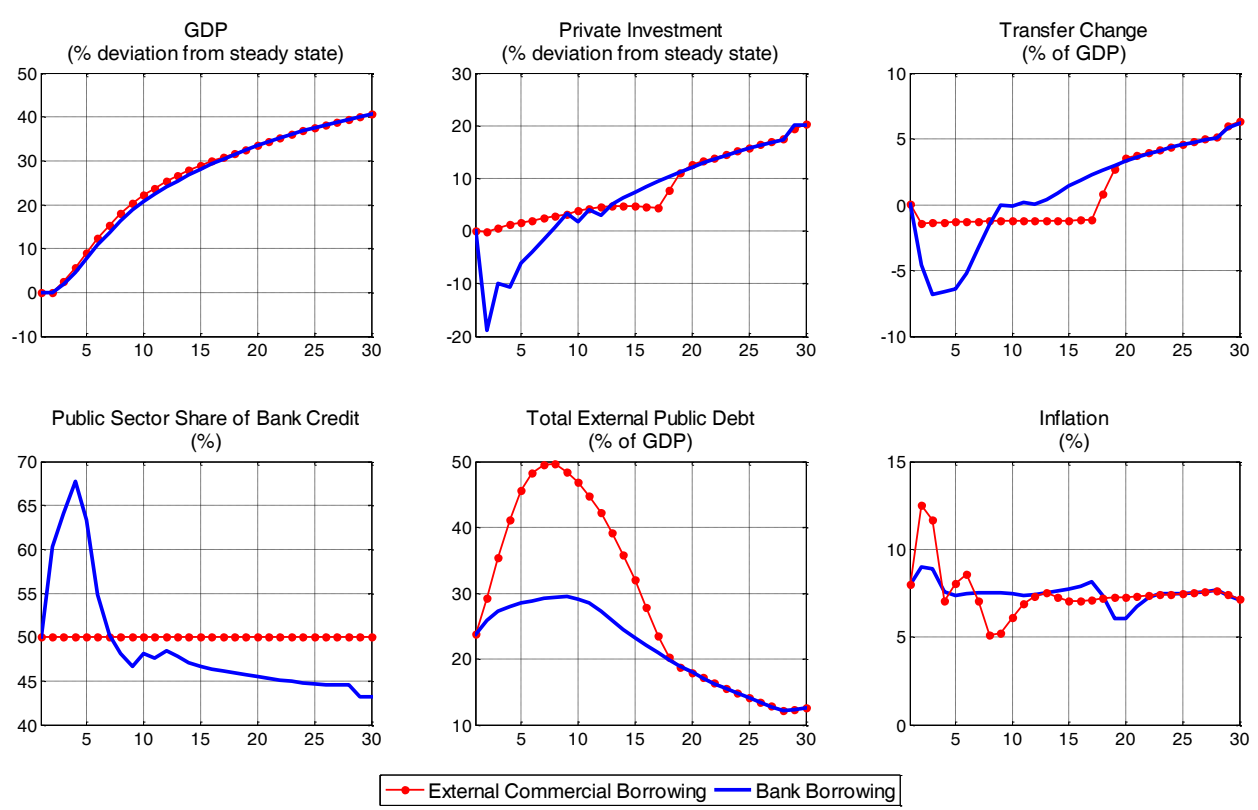

Source: DIG application to Ethiopia (IMF, 2014b). 
Similar applications of introducing an energy sector into the DIG model were completed for Senegal and Lesotho. In Senegal, model simulations revealed that a public investment program that coordinated new investment in low-cost hydroelectric and coal or gas-fired power with a phased contraction of the oil-based sector could have several macroeconomic benefits (Issoufou et al., 2014). For example, such program could raise the total supply of energy by 70 percent and increase real wages and real GDP by more than 10 percent, in the medium term. Although the fiscal deficit could widen by 1 percent of GDP in the short term, the investment program could also deliver fiscal gains of about 4 percent of GDP in the medium term. Model simulations for Lesotho also showed that increases in domestic energy supply could be growth-enhancing, while receipts from selling electricity abroad could ease the fiscal burden (tax increases), which is often associated with big public projects (Andreolli and Abdychev, 2016). Yet, in the transition, debt as well as taxes could rise substantially to pay for this public investment surge.

\section{B. Using the DIG Model to Interpret and Analyze DSA Projections.}

The DIG model was used for counterfactual simulations, using the projections from the standard Excel-based IMF-WB DSA for Togo (Andrle et al., 2012). ${ }^{8}$ Given the projected paths of selected macroeconomic variables, the model was used to back out the implied paths for the structural macroeconomic shocks that would produce such a set of projections. The implied shocks depended on the structure of the model and respective calibration, making judgement critical. To calculate the model-implied structural shocks, the following two approaches were considered: (i) the specification of the stochastic properties for shocks, combined with the application of the Kalman filter to a linearized version of the model, and (ii) the inversion of the non-linear model, while maintaining the assumption of perfect foresight in the deterministic framework. Overall the trajectories of the endogenous variables (output, investment, and so on) were treated as known, both future and past, to solve for the trajectories of shocks required to reproduce the values of such variables in the model. The calibration of the initial conditions matched the data from Togo in 2007-2008.

The Kalman filter application revealed that the initial forecasts from the 2011 IMF-WB DSA for Togo implicitly assumed that the share of exports to GDP would gradually fall over the long run. Part of the decline in exports seemed to reflect an appreciated real exchange rate, which could have been triggered by the investment scaling-up. But the model showed that the assumed decline in exports could reflect unintended negative productivity shocks in the exportable sector. Based on these findings, the projections were corrected for the final version of the 2011 IMF-WB DSA.

\footnotetext{
${ }^{8}$ These projections were from the macroeconomic framework underlying the standard Excel-based DSA.
} 
Figure 13: Inverting the Model Dynamics: Counterfactual Simulations for Per Capita GDP Growth.

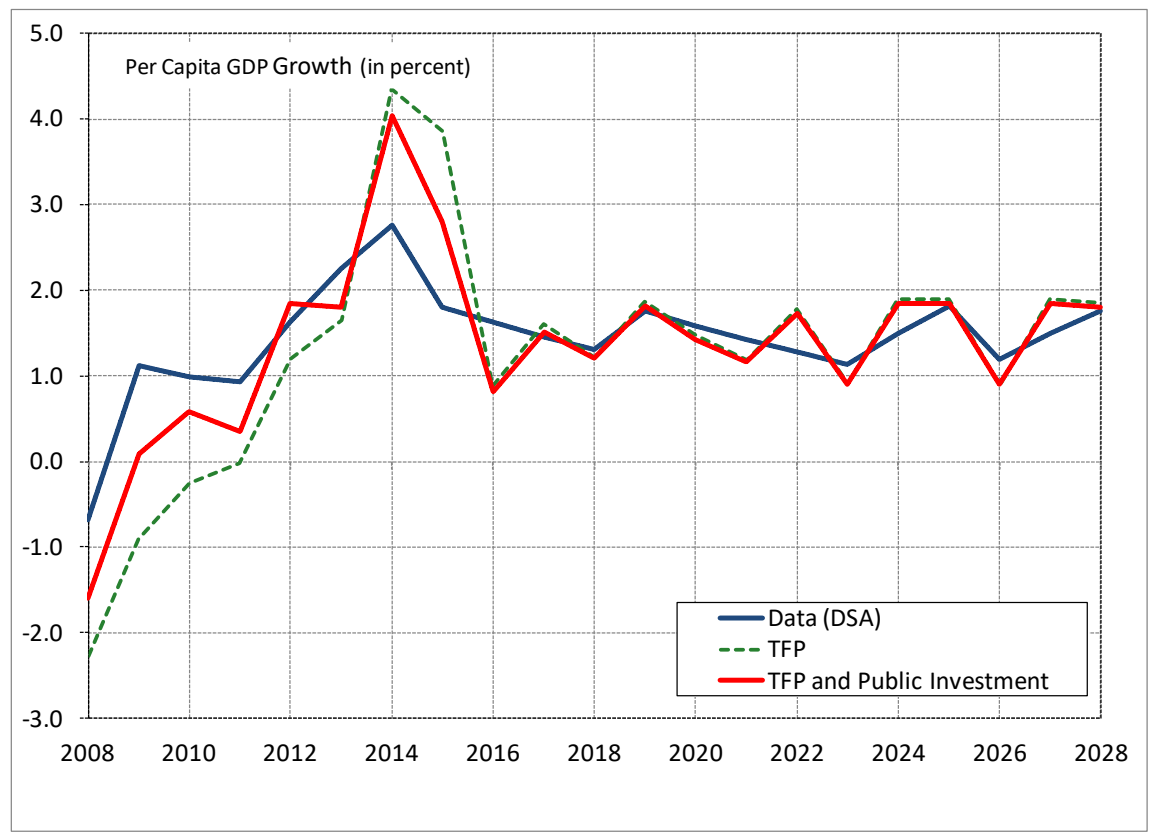

Source: DIG application to Togo (Andrle et al., 2012).

Note: The blue line (Data) corresponds to the percent GDP growth from the 2011 DSA. The red line is the percent GDP growth from the model with both TFP and public investment shocks. The green dotted line corresponds to the percent GDP growth from the model with only TFP shocks.

The approach of inverting the non-linear model was also used to inspect the role of TFP and public investment shocks in explaining the observed and projected GDP growth in the 2011 IMF-WB DSA for Togo. This procedure involved retrieving the shocks - TFP, public investment, remittances, and aid shocks, among others - that allow the DIG model to match the 2011 projections for per capita GDP growth, public investment, external concessional and non-concessional debt, transfers, grants, and remittances, among others. Once these implied shocks were obtained, counterfactual model simulations were conducted to calculate the part of GDP growth explained by (i) only TFP shocks and (ii) only TFP and public investment shocks. The results showed that during 2008-2014, although part of the growth projections was explained by public investment shocks, a large component was actually explained by TFP shocks (Figure 13).

\section{Investing in Public Infrastructure: Roads or Schools?}

Atolia et al. (2017) extended the DIG model to account for human capital. They proposed an explanation of why governments in developing economies invest in roads but not enough in schools, despite scarce human capital. In this extension, human capital was accrued via an optimal decision of households who postpone labor supply and leisure to spend time in 
schools. The capital cost of building schools and all current expenditures to maintain them were assumed to be paid by the government.

The human capital extension of the DIG model illustrated the trade-offs between investing in economic infrastructure (roads) versus investing in social infrastructure (schools). Model simulations demonstrated that the difference on how quickly roads and schools contribute to economic growth was crucial for the optimal allocation of public investment between these two types of capital. Both investments would require similar large upfront costs. However, upgrading economic infrastructure could increase the productivity of private firms relatively quickly, whereas the scaling-up of schools could raise workers' productivity mostly in the long run - albeit potentially to a larger extent. In addition, social infrastructure could entail larger current expenditures, including those associated with operations and maintenance. With these differences and assuming a relatively large return differential of 15 percent in favor of schools, a government seeking to maximize households' welfare, under a "big push," would still limit the fraction of investment in schools to about a half (Figure 14).

\section{Figure 14: Welfare and Share of Schools in the Public Investment Scaling-Up.}

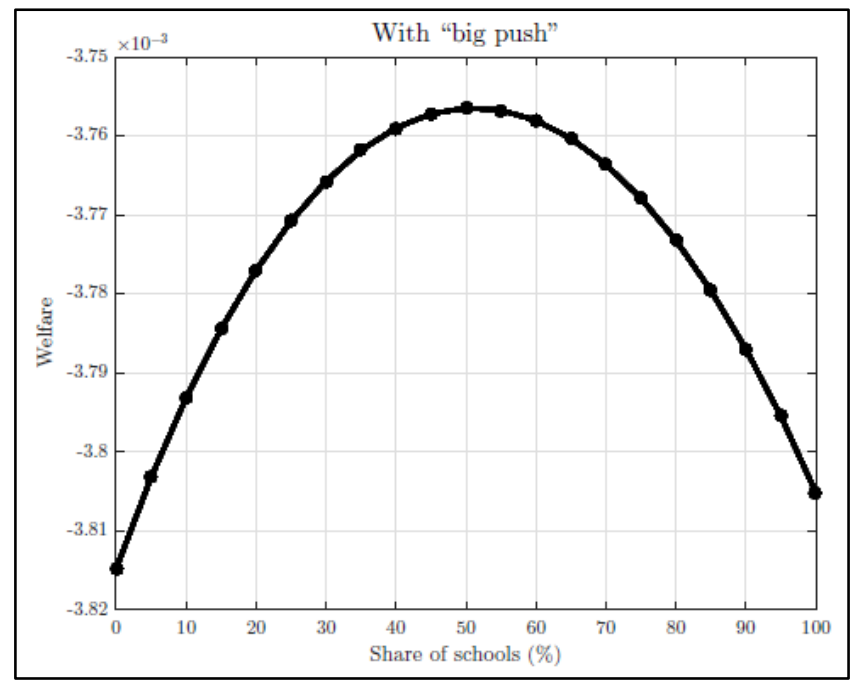

Source: Atolia et al. (2017).

Atolia et al. also argued that political myopia could determine the composition of public investment. The literature on political economy has studied how selfish political leaders could distort the provision of public goods to enhance their chances of getting re-elected (Aidt and Dutta, 2007; Bonfiglioli and Gancia, 2013). These political considerations were introduced in the model by assuming that the incumbents disregard the benefits of policies that arise after a certain time horizon: the greater the selfishness, the higher the political myopia, and therefore the shorter the time horizon. While the ranking of policies was based on the agents' discounted utility flows from consumption, these were summed up over limited time horizons to capture political myopia. Based on this, the extended model simulations revealed that a planner with a horizon of less than 30 years would not invest in 
schools at all. By accelerating growth outcomes, a "big push" could mitigate this myopia, but at the expense of greater risks to fiscal and debt sustainability. Only tied concessional financing and grants could potentially counteract the adverse effects of both debt aversion and political myopia.

\section{Harnessing Resource Wealth for Inclusive Growth in Fragile States.}

Deléchat et al. (2015) extended the DIGNAR model to explore options to reduce poverty through direct cash transfers. They applied the model to the four Mano River Union Countries (MRU) in West Africa, namely Côte d'Ivoire, Guinea, Liberia, and Sierra Leone. All four MRU countries had recently embarked on ambitious development strategies revolving around the exploitation of the resource wealth to scale up public investment, to reach middle-income country status over a decade. Given that resource revenue in these economies was relatively small, model simulations showed the need for the expansion of the tax base, expenditure controls, and improvement in investment efficiency in order to create fiscal space for scaling up public investment.

Figure 15: The Macroeconomic Impact of Social Transfers.

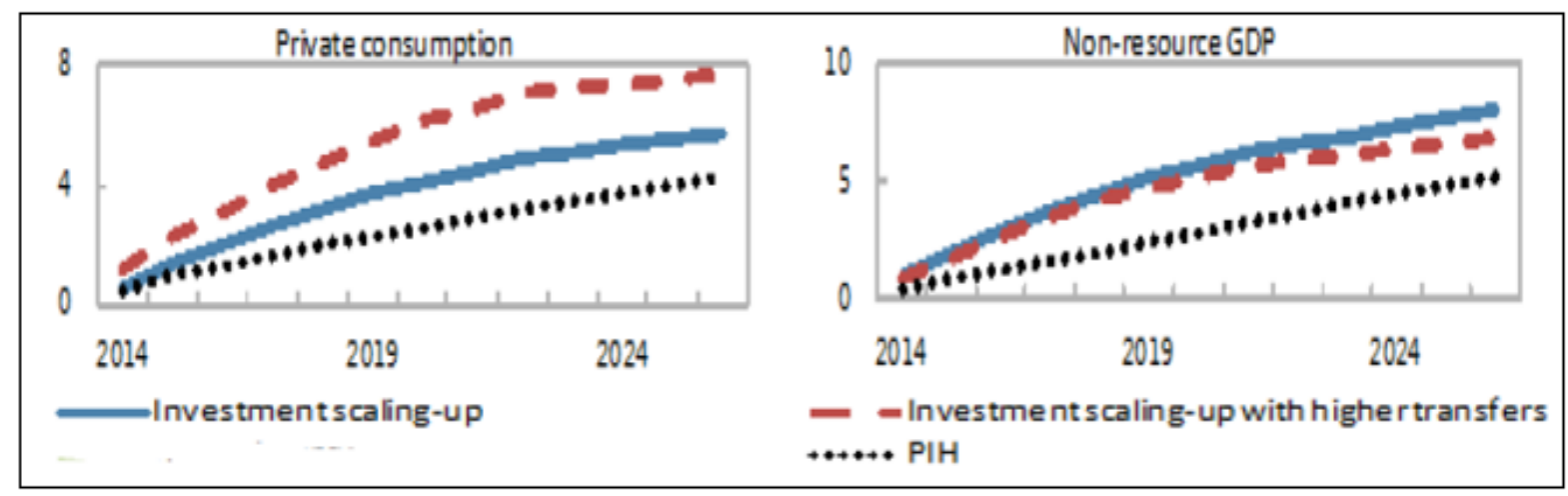

Source: Units of the y-axis are percent deviations from a trend growth path. Deléchat et al. (2015).

In their extension of the DIGNAR model, Deléchat et al. analyzed how some of the resource revenue can be used to fund social transfers and raise private consumption. They proposed that a fraction of this revenue could be used to sustainably expand social safety nets and reduce poverty, raising some interesting trade-offs for policy makers. The Liberia application highlighted, for instance, that while public investment alone would boost non-resource GDP to a slightly greater extent, a fiscal plan that devoted a fraction of the resource revenue to transfers - towards poor financially constrained consumers - could lead to a substantially greater improvement in private consumption (Figure 15). 


\section{E. “Growth-Friendly" Fiscal Consolidations.}

IMF (2016a) used DIGNAR to design a growth-friendly composition of a fiscal adjustment in Namibia. In 2016, country officials had embraced ambitious fiscal consolidation plans, and the key challenge was to minimize the negative effects on growth. The DIGNAR application then compared two types of consolidations: an expenditure-based versus a revenue-and-expenditure-based. Simulations highlighted that a combined strategy of revenue and expenditure measures could lower the negative effects on growth relative to a pure expenditure-based adjustment (Figure 16).

The superiority of a revenue-and-expenditure-based fiscal consolidation reflected the combined effect of two factors. First, the increase in revenue was attained through increasing consumption taxes, which were characterized by having a lower distortionary impact than income tax. Second, the model featured a significant share of financially-constrained poor agents, who consumed their current income period by period and did not increase savings in response to the increase in taxes. Even better growth outcomes could be attained if the revenue-and-expenditure-based fiscal consolidation were accompanied by: (i) a change in the expenditure composition in favor of public investment; (ii) structural reforms in public financial management aimed at raising the level of investment efficiency; and (iii) reforms for improving tax collection efficiency.

\section{Figure 16: The Effects of Expenditure-Based versus Revenue and Expenditure-Based} Fiscal Consolidations.
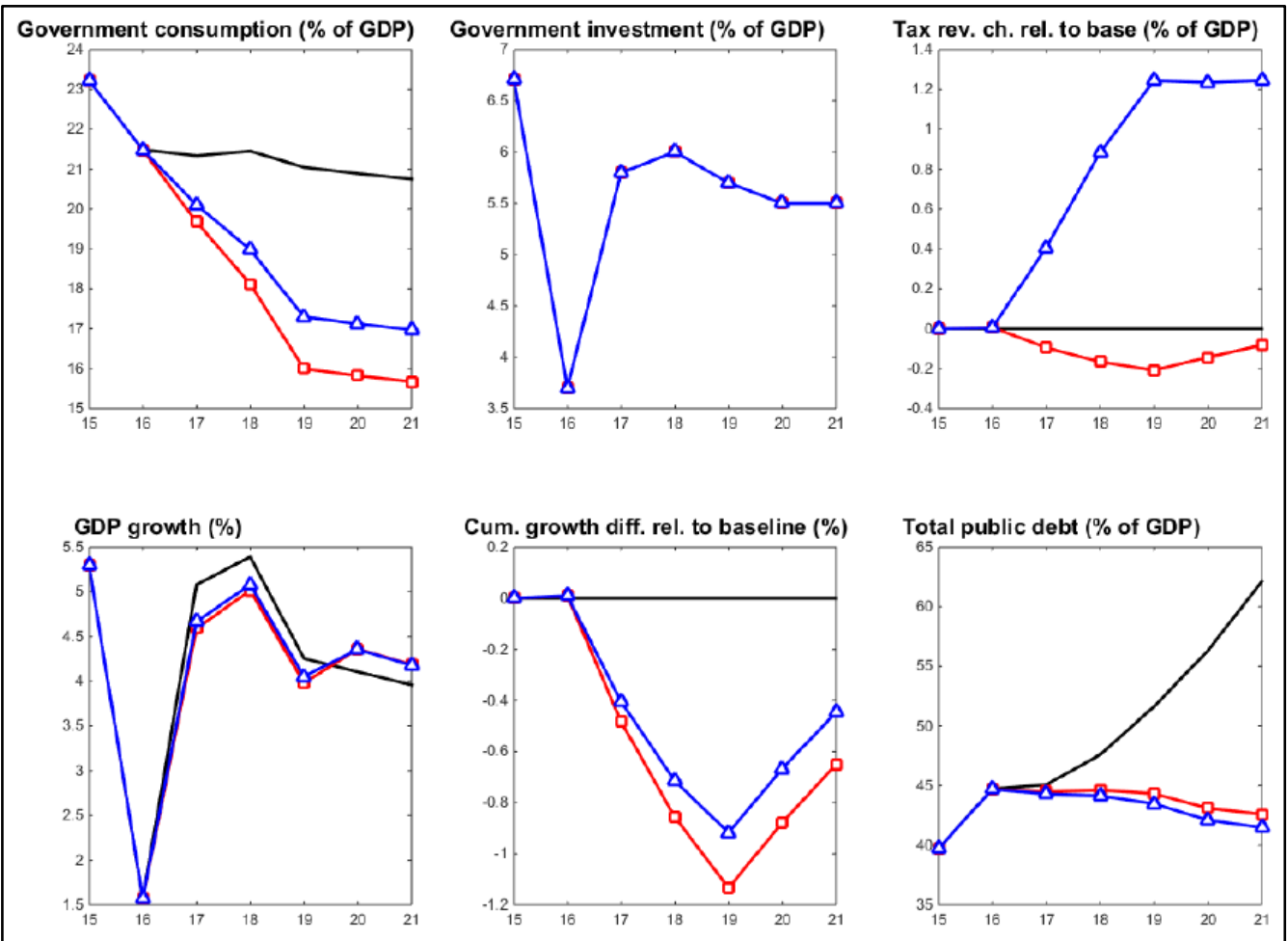

Source: IMF (2016a) 


\section{F. Building Resilience to Natural Disasters.}

Marto et al. (2017) extended the DIG model to capture the challenges of closing infrastructure gaps in developing countries that frequently face natural disasters. They introduced two forms of public capital: standard and adaptation infrastructure. Relative to standard infrastructure, adaptation infrastructure could be complementary-e.g., seawalls, breakwater -retrofitting or climate proofing — or substitute—e.g., climate resilient infrastructure. In this extension, investing in resilience could raise the marginal product of private capital, crowding in private investment, while helping withstand the impact of natural disasters. The government was assumed to maintain a natural disaster fund (NDF) from public savings. In the event of a disaster, reconstruction efforts could then tap into traditional debt instruments - domestic, concessional, and external commercial—and/or savings from the NDF, which worked as domestic buffers. They would also require fiscal adjustment in the form of taxes and/or transfers, to stabilize debt ratios. Natural disasters could affect the economy through the following five effects/channels: a permanent damage to private capital; a permanent damage to public capital; a temporary productivity loss; a decline in public investment efficiency during reconstruction; and a loss in credit worthiness.

Figure 17: Tax and Debt Financed Reconstruction, After a Natural Disaster.

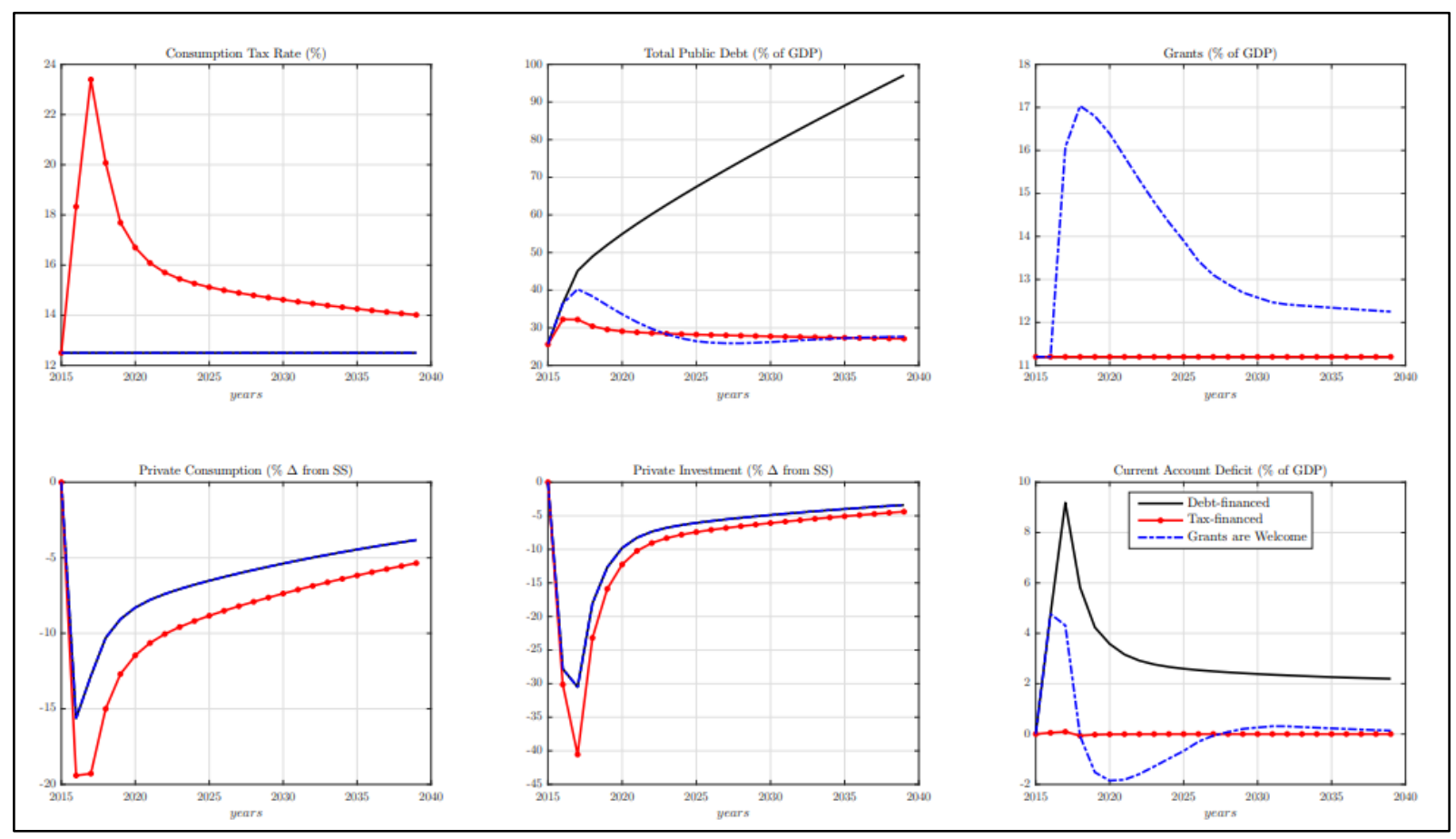

Source: Marto et al. (2017).

The extended model was applied to Vanuatu, which was impacted by a cyclone, to assess the debt sustainability concerns associated with the need to rebuild public infrastructure. The simulation results highlighted the grim fiscal prospects of the country. On the one hand, taxfinanced reconstruction spending could impinge crowding-out effects on private 
consumption and investment that could be as big as 20 and 40 percent declines, respectively (Figure 17). On the other hand, debt-financed spending would quickly lead to unsustainable debt paths. In this challenging context, a viable policy option to absorb the unintended consequences of the reconstruction spending would require a significant big push in grants. Using the model, it was found that the required grant push could amount, on average, to an additional 50 percent of pre-cyclone grants levels, over 15 years after the natural disaster.

\section{Figure 18: The Compounded Security Effect of a Permanent Cut in Foreign Aid.}

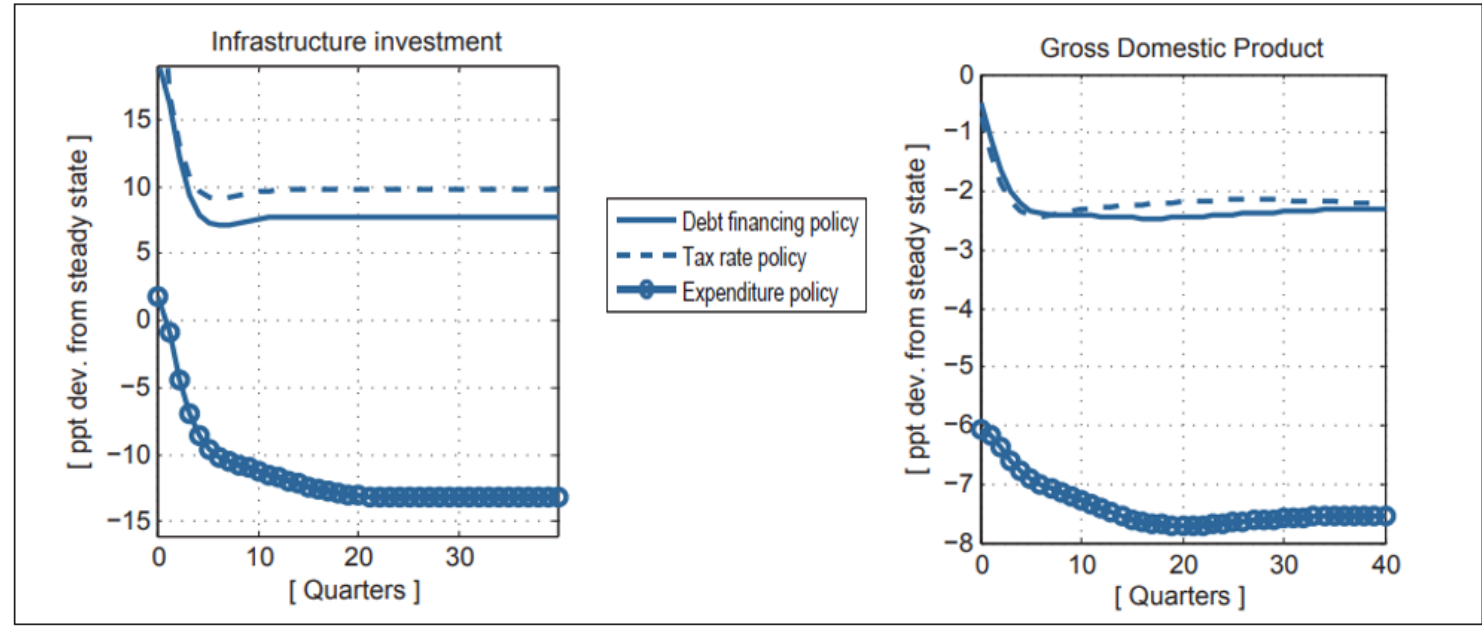

Source: Aslam et. al. (2013).

\section{G. Balancing Social and Security Spending.}

Aslam et al (2013) extended the DIG model to study the trade-offs between investing in infrastructure and raising security spending, in a post-conflict economy. In this framework, the government could provide two public services: security services with the aim of ensuring a stable socio-political climate conducive to growth; and public infrastructure to fulfil development needs. Each type of capital — private capital, infrastructure, and security capital — was accumulated via their respective investment. To model decisions about investment in security, it was assumed that the government agency would maximize the level of public services subject to funding allowances from the central government. The agency then would allocate spending between security and infrastructure, depending on their relative maintenance cost and importance in the production of final public services.

This extension was applied to Afghanistan, to analyze the macroeconomic effects of a withdrawal of foreign troops - a reduction in security services - and a gradual decline of foreign aid. The simulation results showed that a cut in foreign aid would result in lower public investment, leading to a significant contraction in the economy (Figure 18). The negative effect on output was compounded, since it reflected both a decline in infrastructure investment and a cut in security spending. Issuing domestic debt could be one option to protect public investment but, as analyzed in other applications, it would adversely affect 
private investment and consumption. It would also put the country public finances on an unsustainable path. To secure development outcomes, while ensuring the adequate provision of security services, the country would need reforms supporting domestic revenue mobilization-e.g., broadening the tax base by improving tax administration.

\section{H. Governance Reforms.}

IMF (2018c) used the DIG model to analyze governance reforms. In this extension, it was assumed that weak governance could manifest itself via three channels. First, a share of economic output could be lost, where such a loss was assumed to be proportional to the level of production. This could capture the fact that entrepreneurs could be discouraged from investing and hiring, given that they might have to spend time and resources bribing government officials to obtain required authorizations. Second, weak governance could reduce the efficiency of public investment. And third, inefficiencies could lead to losses in tax revenues, since a fraction of taxes might never reach the government budget.

Figure 19: The Effects of Governance Reforms.

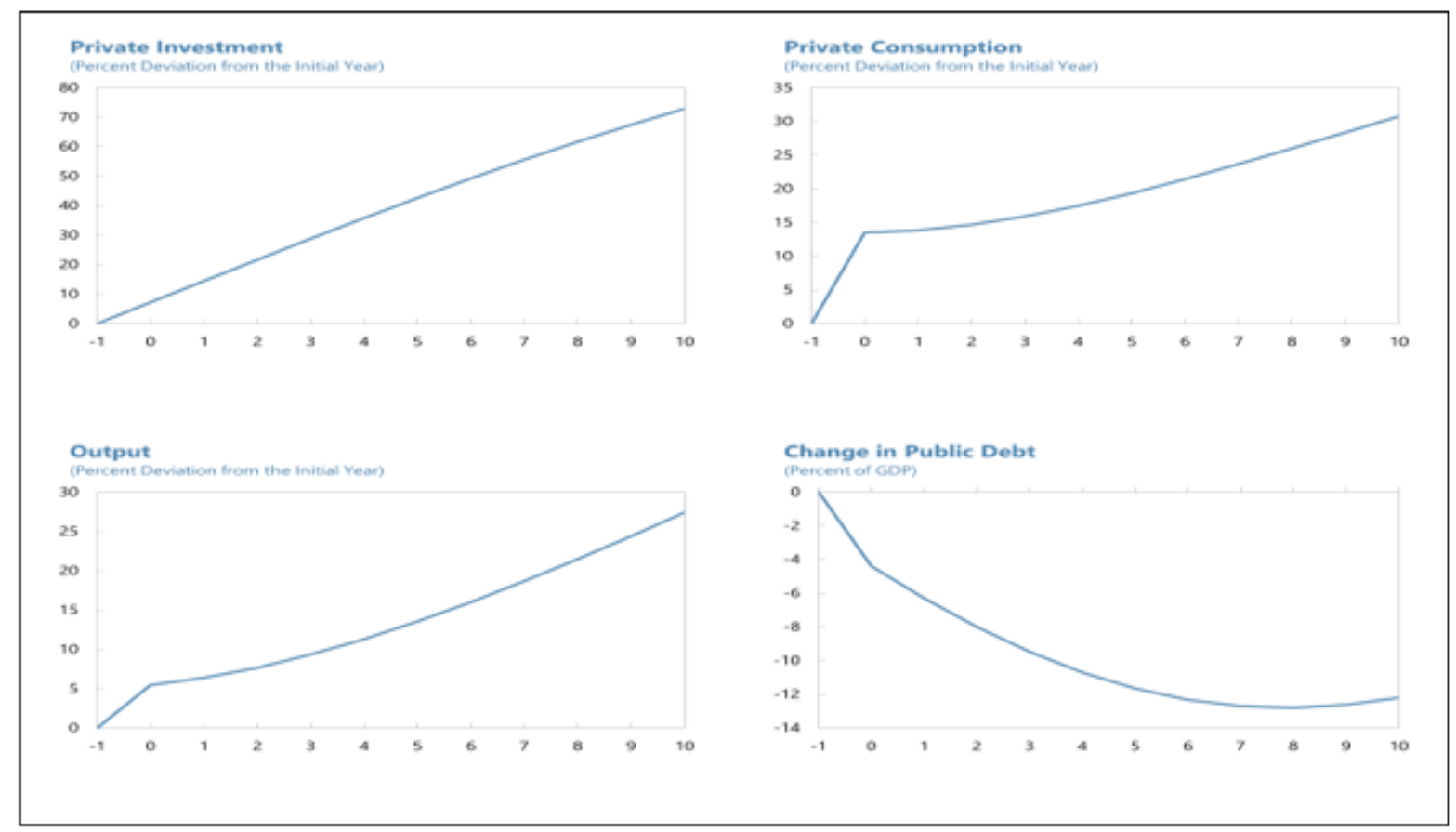

Sources: IMF (2018).

The model was calibrated to a representative Emerging Market and Developing Economy (EMDE), featuring weak governance in the three channels outlined above. Indicators about the efficiency in tax collection and public investment were used to calibrate the corresponding efficiency parameters in the model, at the first quartile of the distribution of EMDEs. Similarly, the share of output lost to weak governance was calibrated to match the ratio of private investment to GDP, at the first quartile of the same group. The simulations of 
this extension also assumed that the country could gradually improve in the three dimensions of governance from the first to the second quartile of the distribution over 10 years.

The simulations results illustrated how a comprehensive reform package improving all three aspects of governance could deliver much higher growth and expand the fiscal space to a great extent (Figure 19). The simulations predicted that private investment would be 70 percent higher, after 10 years, and output and private consumption would increase by about 30 percent. Public debt would fall by almost 15 percent of GDP after 10 years, allowing the tax rate to fall, stimulating private demand even further.

\section{Operations and Maintenance.}

Adam and Bevan (2014) extended the DIG model by explicitly accounting for public spending in operations and maintenance (O\&M) over and above new public investment and studied the implications of financing it through a variety of fiscal instruments. In this extension, deficient maintenance expenditures could lead to higher capital stock depreciation rates, while deficient operations expenditures could reduce the output produced by the current stock of public capital. Unlike the DIG model, Adam and Bevan introduced distortionary taxes to capture the deadweight loss of taxation. These extensions were found to be key in shaping the nexus between public investment increases and growth. Their model simulations revealed that public investment surges that were not matched by a commensurate increase in O\&M could produce substantially lower growth rates.

\section{Conclusions}

This paper has taken stock of more than 65 country applications of the DIG and DIGNAR models. Most of these applications were conducted to complement the IMF-WB debt sustainability analysis work, in the context of Article IV and Program Review missions. The models are well suited to analyze and quantify the effects of public investment on growth and debt, since their DSGE structure facilitates constructing internally consistent and transparent policy scenarios. In this process, these models help organize thinking and build intuition about how various characteristics of an economy and policies interact and matter for simulated outcomes.

The policy lessons from these applications span over a wide range of policy issues that are at the forefront of the development agenda of developing countries. In the context of public investment scaling-ups, these lessons highlight the importance of reforms geared towards improving the efficiency of this investment and raising the rate of return of public projects to maximize the growth pay-offs and lower risks associated with debt accumulation. They also illustrate how the execution plan of public investment projects should consider their potential negative effects on the private sector and absorptive capacity constraints. Because of these 
effects, very ambitious and front-loaded investment plans may induce lower growth in the medium-term than gradual scaling-ups, exacerbating the risks of unsustainable debt.

Moreover, the lessons underscore the macroeconomic importance of domestic revenue mobilization as well as of aid in financing public investment outlays. Both may help contain debt surges that are frequently associated with substantial public investment increases, and aid may also help ease the drastic adjustment of the private sector, amplifying the fiscal impact on output. In natural resource-rich countries, a resource fund where windfalls can be saved, instead of fully invested in public capital, can help mitigate the negative competitiveness effects associated with pronounced real exchange rate appreciations and declines in traded sector output. In addition, the fund can serve as a fiscal buffer that can be used to avert debt sustainability problems in the events of adverse shocks.

From a qualitative point of view, it may be possible to claim that some of these lessons were already known by policy makers, questioning the use of the DIG and DIGNAR models in policy analysis. This view, however, misses a key contribution of these frameworks: the quantification of the macro-effects that are discussed in those lessons. By using countryspecific data in the calibration and simulation of these models, IMF country teams have been able to quantify these effects and incorporate them in their macro policy analysis. In the context of public investment scaling-ups, this work has involved the quantification of fiscal multipliers, the growth benefits of improving public efficiency or of higher returns for public projects, the macroeconomic costs of absorptive capacity constraints, the size of the private demand adjustment and the effects on debt-to-GDP ratios, among others.

The DIG and DIGNAR models are flexible enough to be extended. As of today, the models have been extended to provide policy advice on a wide range of more specific issues, such as investing in the energy sector, social (education) spending, inequality-reducing fiscal measures, climate change-induced natural disasters, security spending, operations and maintenance, governance reforms, and fiscal consolidation. An ongoing project is incorporating richer labor market features in these frameworks to allow for unemployment and, in this way, measure the labor market effects of public investment increases. Against this background, it is then possible to foresee that these models will continue to be used and further extended to help inform policy analysis and advice at the IMF and in other institutions.

There are other lessons that have not been discussed in this paper, but that are equally important in this work of using model-based frameworks for policy and debt sustainability analysis. Some of these lessons pertain to what has been useful about applying these models for policy analysis at the Fund. Overall DIG and DIGNAR have been useful tools for policy makers and mission teams when they have questions that can be addressed through scenario analysis. This is clearly illustrated by the applications of the models discussed in this paper, 
but also by the number and quality of the extensions presented in Section IV, which were born from the need from staff to address some specific policy questions.

There are other uses, however, which are not documented in the applications but had a key positive impact on the staff debt sustainability analysis. In the paper we referred, for instance, to how by using the DIG model for a particular LIC, it was identified that the initial forecasts from the IMF-WB DSA implicitly assumed a decline in exports, reflecting unintended negative productivity shocks in the exportable sector. The projections then were corrected. Similarly, in the context of public investment scaling-ups for another LIC, the difference between the projections of the IMF-WB DSA from those of the DIG model were found to be related to the fact that staff assumed no private sector crowding out, which is featured in the model. This spurred an interesting discussion about views of the transmission mechanism of public investment scaling ups and the degree of crowding out in that country, showing that the model could help organize policy discussions. Once more, after some discussions, the new projections accounted for some crowding out, consistent with the staff views.

Last, the country applications of the DIG and DIGNAR models would have not been possible without the commitment of mission chiefs and their teams. This involved supporting the work associated with it, including learning the structure of the models, calibrating them using country-specific data, and designing and simulating policy scenarios to address their questions. This required time and effort. And in this respect, the applications reminded us that the model simulations and policy scenario analysis go beyond learning the structure of the model and how the codes work. They also involved a detailed study of impulse responses, continuous sensitivity analysis with respect to structural and policy parameters, and, more importantly, persistent interactions with the country teams to ensure that the simulations capture their views about how the economy works as well as their judgement, while still imposing some self-discipline by the models. 


\section{REFERENCES}

Adam, C. and D. Bevan. 2014. "Public Investment, Public Finance, and Growth: The Impact of Distortionary Taxation, Recurrent Costs, and Incomplete Appropriability." IMF Working Paper No. 14/73. International Monetary Fund, Washington, D.C.

Aidt T. and J. Dutta. 2007. "Political Myopia and Economic Growth." European Journal of Political Economy, Vol. 23, pp. 734-753.

Andreolli, M. and A. Abdychev. 2016. "Investing in Electricity, Growth, and Debt Sustainability: The Case of Lesotho.” IMF Working Paper No. 16/115. International Monetary Fund, Washington, D.C.

Andrle, M., A. David, R. Espinoza, M. Mills, and L.F. Zanna. 2012. "As You Sow So Shall You Reap: Public Investment Surges, Growth, and Debt Sustainability in Togo," IMF Working Paper 12/127. International Monetary Fund, Washington, D.C.

Aslam, A., E. Berkes, M. Fukač, J. Menkulasi, and A. Schimmelpfennig. 2013.

"Afghanistan: Balancing Social and Security Spending in the Context of Shrinking Resource Envelope," IMF Working Papers 13/133. International Monetary Fund, Washington, D.C.

Atolia, M., B. G. Li, R. Marto and G. Melina. 2017. "Investing in Public Infrastructure:

Roads or Schools?" IMF Working Papers 17/105. International Monetary Fund, Washington, D.C.

Barro, R. J. 1990. "Government Spending in a Simple Model of Endogeneous Growth." Journal of Political Economy, Vol. 98(5), pp. S103-S125.

Berg, A., R. Portillo, S. C. S. Yang and L. F. Zanna. 2013. "Public investment in resourceabundant developing countries." IMF Economic Review 61, pp. 92-129.

Berg, A., S. C. S. Yang and L. F. Zanna. 2015. "Modeling African Economies: A DSGE Approach," the Oxford Handbook of Africa and Economics: Context and Concepts, eds. C. Monga and J. Lin, Vol. 1, pp. 370-392.

Berg, A., E.F. Buffie, C. Pattillo, R. Portillo, A. Presbitero, and L.F. Zanna. 2018. "Some Misconceptions about Public Investment Efficiency and Growth,” Economica May, pp. 1-22.

Bohn, H. 1998. 'The Behavior of US Public Debt and Deficits,' Quarterly Journal Economics, Vol. 113(3), pp. 949-63.

Bonfiglioli A. and G. Gancia. 2013. "Uncertainty, Electoral Incentives and Political Myopia.” Economic Journal, Vol. 123, pp. 373-400. 
Buffie, E.F., A. Berg, C. Pattillo, R. Portillo, and L. F. Zanna. 2012. "Public investment, growth, and debt sustainability: putting together the pieces." IMF Working Paper 12/144. International Monetary Fund, Washington, D.C.

Christiano, L., M. Eichenbaum, and M. Trabandt. 2018. “On DSGE Models”. Journal of Economic Perspectives 32(3): 113-140.

C. C. Delechat, J. W. Clark JR, P. Gupta, M. Kabedi-Mbuyi, M. Koulet-Vickot, C. Macario, T. Orav, M. Rosales Torres, R. Tapsoba, D. Zhdankin, S. C. S. Yang. 2015. "Harnessing Resource Wealth for Inclusive Growth in Fragile States" IMF Working Paper 15/25. International Monetary Fund, Washington, D.C.

Eaton, J. 2002. "The HIPC Initiative: The Goals, Additionality, Eligibility, and Debt Sustainability." Mimeo (Operations Evaluation Department, World Bank).

Esfahani, H. S. and M. T. Ramirez. 2003. "Institutions, Infrastructure, and Economic Growth," Journal of Development Economics, Vol. 70(2), pp. 443-477.

Ghosh, A., J. I. Kim, E. Mendoza, J. Ostry, and M. Qureshi. 2013. "Fiscal Fatigue, Fiscal Space and Debt Sustainability in Advanced Economies.” Economic Journal, F4-F30.

Hjertholm, P. 2003. "Theoretical and Empirical Foundations of HIPC Debt Sustainability Targets.” Journal of Development Studies, Vol. 39, pp. 67-100.

Hulten, C. 1996. "Infrastructure Capital and Economic Growth: How Well You Use It May Be More Important Than How Much You Have.” NBER Working Paper, No. 5847.

International Monetary Fund (IMF). 2013a. "Republic of Kazakhstan Selected Issues", IMF Country Report 13/291. International Monetary Fund, Washington, D.C.

International Monetary Fund (IMF). 2013b. "Mozambique Staff Report", IMF Country Report 13/200. International Monetary Fund, Washington, D.C.

International Monetary Fund (IMF). 2014a. "Macroeconomic Developments in Low-Income Developing Countries: 2014 Report," IMF Report, International Monetary Fund, Washington, DC.

International Monetary Fund (IMF). 2014b. "The Federal Democratic Republic of Ethiopia Selected Issues Paper”, IMF Country Report 14/304. International Monetary Fund, Washington, D.C.

International Monetary Fund (IMF). 2015. "Financing for development: Revisiting the Monterrey Consensus," IMF Policy Paper, International Monetary Fund, Washington, DC.

International Monetary Fund (IMF). 2016a. "Namibia - Selected Issues Paper", IMF Country Report 16/374. International Monetary Fund, Washington, D.C. 
International Monetary Fund (IMF). 2016b. "Botswana Staff Report", IMF Country Report 16/103. International Monetary Fund, Washington, D.C.

International Monetary Fund (IMF). 2016c. "Recent Developments and Prospects", in World Economic Outlook, Chapter 1, April 2016. International Monetary Fund, Washington, D.C.

International Monetary Fund (IMF). 2017a. "Review of the Debt Sustainability Framework in Low-Income Countries: Proposed Reforms," IMF Policy Paper, International Monetary Fund, Washington, DC.

International Monetary Fund (IMF). 2017b. "2017 Article IV Consultation, Seventh Review Under the Stand-By Arrangement and Modification of Performance Criteria for the Republic of Serbia," IMF Country Report 17/263, International Monetary Fund, Washington, DC.

International Monetary Fund (IMF). 2018a. "Macroeconomic Developments and Prospects in Low-Income Developing Countries - 2018, ' International Monetary Fund, Washington, DC.

International Monetary Fund (IMF). 2018b. "Domestic Revenue Mobilization in SubSaharan Africa: What Are the Possibilities?", in Regional Economic Outlook-Sub-Saharan Africa, Chapter 2, April 2018. International Monetary Fund, Washington, D.C.

International Monetary Fund. 2018c. "Review of 1997 Guidance Note on Governance-A Proposed Framework for Enhanced Fund Engagement," International Monetary Fund, Washington, D.C.

International Monetary Fund. 2018d. "Public Investment Management Assessment-Review and Update," International Monetary Fund, Washington, D.C.

Issoufou, S., E. F. Buffie, M., Bamba Diop, and K. Thiaw. 2014. "Efficient Energy Investment and Fiscal Adjustment in Senegal," IMF Working Paper No. 14/44. International Monetary Fund, Washington, D.C.

Lucas, R. E. 1988. “On the Mechanics of Economic Development," Journal of Monetary Economics, Vol. 22(1), pp 3-42.

Marto, R., C. Papageorgiou, and V. Klyuev. 2017. "Building Resilience to Natural Disasters: An Application to Small Developing States," IMF Working Paper No. 17/223. International Monetary Fund, Washington, D.C.

Melina, G., S. C. S.Yang, and L. F. Zanna. 2014. "Debt Sustainability, Public Investment and Natural Resources in Developing Countries: The DIGNAR Model." IMF Working Paper 14/50. International Monetary Fund, Washington, D.C.

Melina, G., S. C. S.Yang, and L. F. Zanna. 2016. "Debt Sustainability, Public Investment and Natural Resources in Developing Countries: The DIGNAR Model." Economic Modelling, Vol 52 (Part B), pp. 630-49. 
Pritchett, L. 2000. "The Tyranny of Concepts: CUDIE (Cumulated, Depreciated, Investment Effort) is Not Capital," Journal of Economic Growth, Vol. 5, pp. 361-384.

Sachs, J. 2002. "Resolving the Debt Crisis of Low-Income Countries." Brookings Papers on Economic Activity, Vol. 1, pp. 257-286.

Wyplosz, C. 2007. "Debt Sustainability Assessment: The IMF Approach and Alternatives." HEI Working Paper, No. 03/2007 (Graduate Institute of International Studies, Geneva).

Zanna, L.F., E.F. Buffie, A. Berg, C. Pattillo, and R. Portillo. 2019. "Borrowing for Growth: Big Pushes and Debt Sustainability in LICs." Forthcoming in the World Bank Economic Review. 


\section{APPENDIX}

\section{A. List and Web Links of Country Applications}

\begin{tabular}{|c|c|c|c|c|}
\hline Year & Country & Model & Publication Type & Web Link \\
\hline 2011 & Burkina Faso & DI & Staff Report Annex & https://goo.gl/ZD7jmu \\
\hline 2011 & Togo & DIG & Staff Report Annex & https://goo.gl/Quu9PS \\
\hline 2012 & Cabo Verde & DIG & IMF Working Paper & https://goo.gl/K4VJ5T \\
\hline 2012 & Cote d'Ivoire & DIG & Staff Report Annex & https://goo.gl/XAotZ8 \\
\hline 2012 & Liberia & DIG & Staff Report Box & https://goo.gl/yQkhpd \\
\hline 2012 & Rwanda & DIG & Staff Report Box & https://goo.gl/DM2iBC \\
\hline 2012 & Senegal & DIG & Staff Report Annex & https://goo.gl/bPBUxX \\
\hline 2012 & Togo & DIG & IMF Working Paper & https://goo.gl/DaXWJF \\
\hline 2013 & Afghanistan & DIG & IMF Working Paper & https://goo.gl/ExTZji \\
\hline 2013 & Angola & DIGNAR & IMF Working Paper & https://goo.gl/WGQ2LH \\
\hline 2013 & Azerbaijan & DIGNAR & Staff Report Box & https://goo.gl/pbVYtE \\
\hline 2013 & Egypt & DIG & Unpublished & Not available \\
\hline 2013 & Ghana & DIG & Staff Report Annex & https://goo.gl/ibYjpj \\
\hline 2013 & Jordan & DIG & Unpublished & Not available \\
\hline 2013 & Kazakhstan & DIGNAR & Selected Issues Paper & https://goo.gl/3gkry1 \\
\hline 2013 & Liberia & DIG & IMF Working Paper & https://goo.gl/ivjkke \\
\hline 2013 & Morocco & DIG & Unpublished & Not available \\
\hline 2013 & Mozambique & DIGNAR & Staff Report Appendix & https://goo.gl/Y6NX7c \\
\hline 2013 & Mozambique & DIGNAR & IMF Working Paper & https://goo.gl/Ca9xAz \\
\hline 2013 & Tunisia & DIG & Unpublished & Not available \\
\hline 2013 & Yemen & DIG & Unpublished & Not available \\
\hline 2014 & CEMAC & DIG & Selected Issues Paper & https://goo.gl/6ZCZRt \\
\hline 2014 & Chad & DIGNAR & Staff Report Annex & https://goo.gl/BpZY6Z \\
\hline 2014 & Ethiopia & DIG & Staff Report Box & https://goo.gl/mbRDGK \\
\hline 2014 & Ethiopia & DIG & Selected Issues Paper & https://goo.gl/1kRGMn \\
\hline 2014 & LIDC & DIG & WEO Box & https://goo.gl/Lc6xAt \\
\hline 2014 & Myanmar & DIGNAR & Staff Report Annex & https://goo.gl/RPozNV \\
\hline 2014 & Niger & DIGNAR & Selected Issues Paper & https://goo.gl/Y272Eh \\
\hline 2014 & Rwanda & DIG & IMF Working Paper & https://goo.gl/tbzDfs \\
\hline 2014 & Senegal & DIG & IMF Working Paper & https://goo.gl/Khze28 \\
\hline 2015 & Benin & DIG & IMF Working Paper & https://goo.gl/dND7nv \\
\hline 2015 & Botswana & DIGNAR & Staff Report Box & https://goo.gl/4kFTjd \\
\hline
\end{tabular}




\begin{tabular}{|c|c|c|c|c|}
\hline 2015 & CEMAC & DIG & Selected Issues Paper & https://goo.gl/fXngiE \\
\hline 2015 & Congo & DIGNAR & IMF Working Paper & https://goo.gl/m4upL5 \\
\hline 2015 & Côte d'Ivoire & DIGNAR & IMF Working Paper & https://goo.gl/SNXRZX \\
\hline 2015 & Guinea & DIGNAR & IMF Working Paper & https://goo.gl/SNXRZX \\
\hline 2015 & Lesotho & DIG & Staff Report Box & https://goo.gl/HCwnqq \\
\hline 2015 & Liberia & DIGNAR & IMF Working Paper & https://goo.gl/SNXRZX \\
\hline 2015 & Mauritania & DIGNAR & Selected Issues Paper & https://goo.gl/pR5epd \\
\hline 2015 & Mongolia & DIGNAR & Selected Issues Paper & https://goo.gl/XzcFFd \\
\hline 2015 & Mongolia & DIGNAR & Staff Report Appendix & https://goo.gl/ZSY8Fu \\
\hline 2015 & Sierra Leone & DIGNAR & IMF Working Paper & https://goo.gl/SNXRZX \\
\hline 2016 & Burkina Faso & DIG & IMF Working Paper & https://goo.gl/7NGKYY \\
\hline 2016 & Burkina Faso & DIGNAR & Selected Issues Paper & https://goo.gl/ioT9yW \\
\hline 2016 & Cambodia & DIG & Staff Report Box & https://goo.gl/xR9eSK \\
\hline 2016 & Colombia & DIGNAR & Staff Report Box & https://goo.gl/x46Tib \\
\hline 2016 & Ethiopia & DIG & Staff Report Box & https://goo.gl/5cq8AF \\
\hline 2016 & Guinea & DIG & Selected Issues Paper & https://goo.gl/x4dXpQ \\
\hline 2016 & Kyrgyz Republic & DIG & Staff Report Annex & https://goo.gl/LLnt1X \\
\hline 2016 & Lesotho & DIG & IMF Working Paper & https://goo.gl/Qi1YKM \\
\hline 2016 & Maldives & DIG & Staff Report Annex & https://goo.gl/8gECdi \\
\hline 2016 & Namibia & DIGNAR & Selected Issues Paper & https://goo.gl/Efu629 \\
\hline 2016 & Vanuatu & DIG & Staff Report Annex & https://goo.gl/B9YPPh \\
\hline 2016 & WEO (April 2016) & DIGNAR & WEO chapter & https://goo.gl/Yv1bgC \\
\hline 2017 & Cambodia & DIG & IMF Working Paper & https://goo.gl/4EkrVF \\
\hline 2017 & Serbia & DIG & Staff Report Annex & https://goo.gl/kf4cCw \\
\hline 2017 & Sri Lanka & DIG & IMF Working Paper & https://goo.gl/4EkrVF \\
\hline 2017 & Thailand & DIG & Staff Report Box & https://goo.gl/vaEYBf \\
\hline 2017 & Timor-Leste & DIG & Staff Report Annex & https://goo.gl/yJLmmc \\
\hline 2017 & Vietnam & DIG & IMF Working Paper & https://goo.gl/4EkrVF \\
\hline 2018 & Bolivia & DIGNAR & Unpublished & Not available \\
\hline 2018 & Iran & DIGNAR & IMF Working Paper & https://goo.gl/Qj6yif \\
\hline 2018 & Israel & DIGNAR & Selected Issues Paper & https://goo.gl/64yhuf \\
\hline 2018 & Lesotho & DIGNAR & Unpublished & Not available \\
\hline 2018 & Madagascar & DIG & Selected Issues Paper & https://goo.gl/wRLmhT \\
\hline 2018 & Solomon Island & DIG & Selected Issues Paper & https://goo.gl/ouEBrU \\
\hline 2018 & Western Balkans & DIG & EUR Departmental paper & https://goo.gl/V2apCE \\
\hline
\end{tabular}

